in vivo $35: 3073-3095(2021)$

doi:10.21873/invivo.12603

\title{
Adaptive Membrane Fluidity Modulation: A Feedback Regulated Homeostatic System and Target for Pharmacological Intervention
}

\author{
ELZBIETA IZBICKA $^{1 *}$, ROBERT T. STREEPER ${ }^{1 *}$ and CHRISTOPHER LOUDEN ${ }^{2}$ \\ ${ }^{1}$ New Frontier Labs LLC, San Antonio, TX, U.S.A.; \\ ${ }^{2}$ Louden Consulting, Bandera, TX, U.S.A.
}

\begin{abstract}
Background/Aim: Alterations of plasma membrane fluidity are characteristic of many diseases but the intentional modulation of membrane fluidity with drugs has been less studied. We examined the therapeutic potential of the membrane fluidizer diethyl azelate (DEA) and related azelates. Materials and Methods: The effects of azelates on plasma membrane fluidity and cell signaling were examined in primary human and murine cells and in vivo. Endpoints were queried using single target and multiplexed immunoassays. Results: Unique membrane-fluidizing properties and biomarker signatures suggest that azelates are not prodrugs. DEA decreased cytokine signaling from pattern recognition receptors in human dendritic cells, disabled membrane attack of cholera toxin in vitro, and prevented immunosuppression by anthrax lethal toxin in vitro and in vivo. In the murine sepsis model, DEA increased survival and reduced organ damage. Conclusion: Azelates represent a new class of drugs, membrane active immunomodulators, which target an innate homeostatic mechanism, adaptive membrane fluidity modulation.
\end{abstract}

The interactions of plasma membrane proteins with soluble signaling molecules constitute a significant part of the flow of information between cells and their surrounding environment (1). Temporal and conditional fluctuations of the fluidity and lipid composition of the plasma membrane affect cellular communications by alteration of the activity of membraneassociated proteins. For example, changes of membrane

This article is freely accessible online.

*These Authors contributed equally to this work.

Correspondence to: Elzbieta Izbicka, New Frontier Labs LLC, 900 NE Loop 410, suite D-119, San Antonio, TX, U.S.A. Tel: +1 2107256868, e-mail: eizbicka.g4@gmail.com

Key Words: Azelaic acid ester, azelate, biomarker, plasma membrane. structure and composition can alter inflammatory signaling (2) and innate immune responses (3). Although the influence of membrane structure on cellular signaling is generally accepted, the mechanics of the process are still debated (4-7).

Membrane fluidity is regulated by, among other factors, the relative concentrations of sterols and phospholipids (8). A familiar example is cholesterol, which organizes and rigidifies plasma membranes $(9,10)$. Cholesterol-enriched ordered lipid domains known as lipid rafts contain over $75 \%$ of all membrane lipids and regulate protein diffusion and distribution (11). High blood plasma levels of cholesterol are associated with adverse health outcomes in various diseases including cancer (12-15). On the other hand, lowering the cholesterol content in the plasma membrane can bring beneficial health effects (16-18). Yet, despite a wealth of data supporting the importance of plasma membrane fluidity, intentional alteration of the biophysical properties of the plasma membrane has been explored very little as a therapeutic approach.

We hypothesized that it is possible to modulate the activities of membrane-associated proteins through alteration of plasma membrane fluidity using lipid-soluble molecules and that this approach may be useful for the treatment of human and animal diseases. We became intrigued by azelaic acid, a naturally occurring dicarboxylic acid, which plays a role in systemic immunity in plants (19). Azelaic acid has anti-inflammatory and antimicrobial activity and is used clinically in the treatment of skin diseases (20-22). Both azelaic acid and its esters are naturally produced in humans and other mammals via the oxidative metabolism of oleic and palmitoleic acid moieties of phospholipids and triglycerides $(23,24)$. Exogenous azelaic acid and its compounds have been part of the human diet for many millennia due to their occurrence in olives, grains, grain products, and fermented foods (25-30).

We have previously conducted a clinical study that demonstrated health benefits of oral diethyl azelate (DEA) on surrogate markers of insulin resistance, such as blood plasma glucose, insulin and lipids, when administered to overweight or obese adult male volunteers (31-33). We also 
compared effects of azelates and select esters of other medium chain dicarboxylic fatty acids (C8; suberic acid and C10; sebacic acid) on blood plasma glucose levels. First, the azelates were superior to suberates and sebacates. Second, DEA displayed an inverted U-shaped dose effect with significant antihyperglycemic activity. In addition, the various esters and parent acids had markedly different effects. In a side-by-side comparison of DEA to its diesters (methyl, isopropyl, 2-pentyl, and cyclohexyl), diethyl sebacate and sebacic acid, all compounds significantly differed from each other in affecting glucose AUCs. DEA was clinically active at a dose 400 times lower than sebacic acid, which differs from azelaic acid by a single methylene moiety in the backbone of the diacid (32).

This work describes our further investigation on azelates' mechanism of action in human and murine primary cells and in animal models. We found that the azelates modified plasma membrane fluidity in a structure-related manner and affected the activities of multiple membrane proteins relevant for innate immune responses resulting in altered patterns of signaling molecules produced by human and animal cells.

\section{Materials and Methods}

Chemical synthesis. All reagents for the chemical synthesis were sourced from Sigma Chemical (St. Louis, MO, USA). Eight alkyl azelaic acid esters (azelates) were synthesized in acid-catalyzed esterification reactions (34) from azelaic acid and respective alcohols (methyl, ethyl, propyl, isobutyl, 1-, 2-, and 3-pentyl, and cyclohexyl) using the standard acid-catalyzed esterification to produce dimethyl azelate (DMA), diethyl azelate (DEA), diisopropyl azelate (DiPA), di-isobutyl azelate (DiBU), di-(1-pentyl) azelate (D1PA), di-(2-pentyl) azelate (D2PA), di-(3-pentyl) azelate (D3PA), and dicyclohexyl azelate (DCHA). Following solvent removal from the esters that had an appearance of clear, slightly yellow oils, the esters were purified by fractional distillation at reduced pressure and analyzed by mass spectrometry. The purity of the final product was $>95 \%$.

In silico toxicity and in vitro genotoxicity (Ames) test. Derek ${ }^{\mathrm{TM}}$ for Windows_11.0.0 with knowledge base version DfW11.0.0_05_10_2008 (Lhasa Ltd, Leeds, UK) was used to perform predictive toxicity analysis for bacterium and mammalian species. Queried super-endpoints were carcinogenicity, chromosome damage, genotoxicity, hepatotoxicity, HERG channel inhibition and irritation. Miscellaneous endpoints included mutagenicity, ocular, reproductive and thyroid toxicities, as well as respiratory and skin sensitizations. Genotoxicty of the azelates was examined using ChromoTest assay kit (EBPI, Burlinton, Ontario, Canada) following the manufaturer's protocol. The azelates were tested at $0.0006 \%$ to $10 \%$ concentrations, corresponding to the intended clinical dose ranges.

Cell proliferation and cytotoxicity assays. CellTiter 96 Non-Radioactive Cell Proliferation Assay (MTT), CellTiter 96 AQueous One Solution Cell Proliferation Assay (MTS) and CellTiter-Glo Luminescent Cell Viability (ATP) kits were purchased from Promega (Madison, WI,
USA). The assays were performed according to the supplier's instructions. Protein concentration was measured using Micro BCA protein assay kit (Pierce Biotechnology, Rockford, IL, USA).

Isolation of human peripheral blood mononuclear cells. Fresh human peripheral blood mononuclear cells (PBMC) specimens were obtained from healthy volunteers. The phlebotomy protocol (BT-H12-008) was approved by the Institutional Review Board at BTNS LLC, San Antonio, TX, USA. Whole peripheral blood was collected into BD Vacutainer CPT Cell Preparation Tubes (Beckton Dickinson, Franklin Lakes, NJ, USA) and centrifuged at 1,500 $\times g$ at room temperature, then PBMCs were isolated according to supplier's protocol. Cell counts and viability assessment using trypan blue exclusion were measured using hemocytometer.

Membrane fluidity measurements. Membrane fluidity was measured using Membrane Fluidity Kit (PN M0271, Marker Gene Technologies, Eugene, OR, USA). PBMCs were isolated as described, washed and adjusted to $7 \times 10^{5}$ cells $/ \mathrm{ml}$ in phenol-red free RPMI1640 medium with 10\% fetal bovine serum (FBS) (Thermo Fisher Scientific, Waltham, MA). Sixty thousand cells per well were plated in triplicate in 96-well Acrowell filter plates (PN5021, Pall Corporation, Port Washington, NY, USA) and treated with $1 \mu \mathrm{M}$ pyrenedecanoic acid alone or in the presence of azelates or cholesterol in logarithmic serial dilutions from $100 \mu \mathrm{M}$ to $0.1 \mu \mathrm{M}$ in the final volume of $200 \mu \mathrm{l}$ per well with gentle mixing in the dark for $20 \mathrm{~min}$. The cells were washed twice and reconstituted in 100 $\mu \mathrm{l}$ medium. The fluorescence of the excimer (excitation at $355 \mathrm{~nm}$, emission at $460 \mathrm{~nm}$ ) was corrected for the monomer (excitation at $355 \mathrm{~nm}$, emission at $400 \mathrm{~nm}$ ). The ratios of the monomer to excimer fluorescence were used to quantify the membrane fluidity.

EpiDerm Bioassays. The EpiDerm ${ }^{\mathrm{TM}}$ 3-Dimensional Skin Model was purchased from MatTek Corporation (Ashland, MA, USA) and the tissues were handled according to the supplier's instructions. Briefly, the tissues were equilibrated overnight in 6-well plates, the cell culture medium was replaced and the tissues were incubated with the fresh medium and the test articles. Azelates and azelaic acid sodium salt were tested in triplicate at varying concentrations up to $25 \% \mathrm{w} / \mathrm{v}$ either alone or in combination with $0.1 \%$ croton oil used as an irritant for $24 \mathrm{~h}$. Upon completion of the experiment, conditioned media were collected, the remaining tissues were homogenized on ice in the presence of protease and phosphatase inhibitors and the lysates were clarified by centrifugation. The conditioned media and cell lysates were snap frozen at $-70^{\circ} \mathrm{C}$.

Multiplexed immunoassays. Cytokine, Chemokine and Growth Factors comprising Panel \#1 (54 analytes) and Panel \#2 (36 analytes), Human MMP 3Plex Panel, and Plexable Mouse Cytokine, Chemokine and Growth Factors (37 analytes) were obtained from Affymetrix, Fremont, CA, USA. The specimens (plasma, conditioned media, tissue extracts) were tested at dilutions recommended by the supplier. If not used freshly within $1 \mathrm{~h}$ of sample collection, frozen specimens were thawed on ice and assayed in duplicate or triplicate as described for murine (35) and human (36) assays. Pooled normal human plasma (SeraCare, Milford, MA, USA) was used as a positive control in all assays. Multiplexed immunoassays were performed using Luminex 100 IS System (Luminex Corporation, Austin, TX, USA). Analyte concentrations were calculated from the standard curves using BioPlex Manager 4.1.1 (Bio-Rad Laboratories, Hercules, CA, USA). 
Pathogen-associated molecular pattern receptor agonist studies: Pathogen-associated molecular pattern (PAMP) receptor agonists were purchased from InvivoGen (San Diego, CA, USA). The following agonists were used: A. Human toll-like receptor (TLR1-9) agonist kit containing ligands representing 5 bacterial pathogens; Pam3CSK4 (hybrid TLR1/2;0.1 $\mu \mathrm{g} / \mathrm{ml}$ ), heat-killed preparation of Listeria monocytogenes (HKLM); (TLR2, $10^{7}$ cells $/ \mathrm{ml}$ ), E. coli K12 LPS (TLR4, $100 \mathrm{ng} / \mathrm{ml}$ ), Salmonella typhimurium flagellin (TLR5, 100 ng/ml), FSL-1 (Pam2CGDPKHPKSF) (TLR6, $10 \mathrm{ng} / \mathrm{ml}$ ), and 4 viral pathogens; Poly(I:C) LMW, (TLR3, $10 \mu \mathrm{g} / \mathrm{ml}$ ), imiquimod R837 (TLR7, $1 \mu \mathrm{g} / \mathrm{ml}$ ), single stranded RNA (ssRNA40; TLR8, $1 \mu \mathrm{g} / \mathrm{ml}$ ), and $\mathrm{CpG}$ (TLR9, $5 \mu \mathrm{M}$ ). B. Fungal pathogen ligand; heat-killed Candida albicans (HKCA) at $10^{8}$ cells $/ \mathrm{mL}$ (dectin-1 agonist). C. Bacterial NOD agonists: 1) NOD1; C12-iE-DAP (100 ng/ml), iE-DAP $(1 \mu \mathrm{g} / \mathrm{ml})$, and Tri-DAP (100 ng/ml), 2) NOD2; L18-MDP, and MDP, murabutide (10 ng/ml each), and 3) hybrid NOD1/2; M-TriDAP, and peptidoglycans PGN-ECndi (insoluble peptidoglycan from E. coli K12), PGN-EChyndss (soluble sonicated peptidoglycan from E. coli), and PGN-Sandi (insoluble peptidoglycan from S. aureus) at $100 \mathrm{ng} / \mathrm{ml}$ each. The concentrations of the agonists were in the physiological ranges as recommended by the supplier of the agonists.

Plasmacytoid human dendritic cells (further referred to as dendritic cells) were purchased from MatTek Corporation, Ashland, MA, USA. To examine competition between DEA and the receptor agonists, dendritic cells were washed with RPMI 1640 with $10 \%$ FBS, diluted to $1.6 \times 10^{5}$ cells $/ \mathrm{ml}$ and incubated with PAMP agonists at the concentrations in the middle ranges recommended by the supplier in the absence of DEA (vehicle control; $0.5 \%$ Tween-20 in PBS) or with $0.5 \%$ DEA in vehicle for $24 \mathrm{~h}$. Dendritic cells preparations were also used to compare effects of DEA and azelaic acid, both tested at $0.5 \%$ as above. The media and cells were processed as described for EpiDerm tissues. The levels of ATP and 57 cytokines produced by the cells were normalized to the numbers of viable cells.

Lipid raft visualization. Fluorescent labeling of lipid rafts in human PBMCs was performed using Vybrant Alexa Fluor 488 Lipid Rafts Labeling Kit (PN V-34403, Life Technologies, Grand Island, NY, USA). PBMCs $\left(1 \times 10^{6}\right.$ cells in $0.2 \mathrm{ml}$ RPMI medium with $10 \%$ FBS in the absence or the presence of $0.5 \%$ DEA, quadruplicate repeats) were labeled with the fluorescent cholera toxin subunit B (CT-B) conjugate in for $10 \mathrm{~min}$ at $4^{\circ} \mathrm{C}$, transferred to poly-lysine coated coverslips, washed with cold phosphate buffered saline (PBS), and cross-linked with the anti-CT-B antibody according to the supplier's instructions. The cells were fixed in $4 \%$ formaldehyde, washed with cold PBS with $0.1 \%$ bovine serum albumin and mounted in dry Vectashield (Vector Laboratories, Burlingame, CA, USA). Images were acquired using Zeiss LSM710 scanning confocal microscope; fluorescent imaging was done using argon laser illumination.

Bacterial preparation of Panton-Valentine leukocidin-positive methicillin-resistant Staphylococcus aureus. The bacterial strain, PantonValentine leukocidin-positive methicillin-resistant Staphylococcus aureus [PVL(+) MRSA strain TCH1516; USA300 HOU MR PVL(+)MRSA (ATCC BAA-1717)] and all bacterial culture supplies were purchased from the American Type Culture Collection (Manassas, VA, USA). Bacterial stock was reconstituted according to the supplier's protocol. The bacteria were maintained on Lowenstein-Jensen medium. Colonies from the medium were subcultured in ATCC Medium 18 in trypticase soy agar broth. To prepare bacterial antigens, bacterial suspensions were centrifuged at $10,000 \times g$ for $30 \mathrm{~min}$ at room temperature, resuspended in $2 \mathrm{ml}$ PBS to yield $2 \times 10^{7} \mathrm{CFU} / \mathrm{ml}$, then disrupted by ultrasonication on ice in $30 \mathrm{~s}$ intervals for $5 \mathrm{~min}$. PBS was then added to a final volume of $5 \mathrm{ml}$ and the solution was clarified by sequential filtration through $0.45 \mu \mathrm{m}$ and $0.22 \mu \mathrm{m}$ cellulose acetate syringe filters. Sterility was confirmed by streaking $10 \mu \mathrm{l}$ of the antigen preparation on a tripticase soy agar plate following incubation for $24 \mathrm{~h}$ at $37^{\circ} \mathrm{C}$ in $5 \% \mathrm{CO}_{2}$ atmosphere. Bacterial lysates were adjusted to contain $10^{6} \mathrm{CFU}$ in $50 \mu \mathrm{l}$ per well in EpiDerm tissue plates (MatTek Corporation, Ashland, MA, USA). Processing of the tissue followed the protocol described above. In growth inhibition experiments, the bacteria were exposed to varying concentrations of DEA, which was adsorbed onto a 5\% bovine serum albumin in PBS to affect aqueous phase dispersibility. Bacterial growth was determined by measuring the optical density of the growth medium at $600 \mathrm{~nm}$ in a microplate reader.

In vivo studies. Male and female Balb/c mice 8-10 weeks old weighing approximately $25 \mathrm{~g}$ were purchased from Taconic Farms (Hudson, NY, USA). Animals were acclimatized to laboratory surroundings for at least $72 \mathrm{~h}$ after delivery. Mice were housed in a temperature-controlled room $\left(22^{\circ}\right.$ to $\left.24^{\circ} \mathrm{C}\right)$ with a 12 -h light/dark cycle and were fed ad libitum with Purina 5000 rodent diet and purified water. Three to four mice were maintained in open-top plastic cages with tops covered with stainless wire grid lids, and the cage floors were covered with wood chips, which were changed twice weekly. Animal health and behavior were monitored twice daily. The environment including recommended temperature, light, housing and food was provided to minimize suffering and distress. Veterinary service and consultation were available if needed. For all experiments animals showing debilitation of major morbidity including loss of greater than $20 \%$ of body weight were to be euthanized. These criteria were followed in all cases, except for was the survival experiment using PVL(+) MRSA, in which death was the endpoint. The duration of the study was intentionally made short $(76 \mathrm{~h})$ to minimize pain and suffering. The considerations of the anticipated mortality were addressed in the approved protocol. Prior to experiments, the animals were randomized into treatment and control groups. Based on power calculations and to compensate for possible losses, 7 to 10 mice per group were used, except for acute DEA toxicity tests with 5 mice per group. Experimental protocols used throughout the studies were approved by the Institutional Animal Care and Use Committee at BTNS LLC, San Antonio, TX, USA (protocols number BT-009-004 and BT-011-008). Upon completion of the experiments the animals were euthanized by cervical dislocation, since chemical means would interfere with cytokine level determination endpoints. All procedures were performed in compliance with the Animal Welfare Act Regulations (9 CFR 3) and the NIH guidelines for the care and use of laboratory animals.

Acute toxicity of DEA. Acute toxicity was determined with a single dose of topical and oral DEA $(5 \mathrm{~g} / \mathrm{kg}$ ) that was applied to animals to 5 female mice per group, after a 4 -h fasting period. At 14 days posttreatment, the animals were sacrificed and the gross examination and histochemical staining were performed to determine toxic effects on target organs (liver, lung, kidneys, gastrointestinal tract).

Intoxication with anthrax lethal toxin. Anthrax lethal factor (LF) and anthrax protective antigen (PA) recombinant nicked from Bacillus anthracis were purchased from List Biological Laboratories, Campbell, CA, USA. To determine activity of DEA in anthrax lethal toxin (LT) intoxication, 10 mice were given a single intravenous (i.v.) injection of a non-lethal dose of LT (10 $\mu \mathrm{g}$ 
$\mathrm{LF}+10 \mu \mathrm{g}$ PA) plus a single subcutaneous injection of DEA (50 $\mathrm{mg} / \mathrm{kg}$ ), and 10 mice were given LT alone. After $24 \mathrm{~h}$ the animals were exsanguinated and the blood was separated into plasma and cells as described above for human PBMCs. Briefly, mice were terminated by cervical dislocation, exsanguinated, whole peripheral blood was collected into BD Vacutainer CPT Cell Preparation Tubes (Beckton Dickinson, Franklin Lakes, NJ, USA) and centrifuged at $1,500 \times \mathrm{g}$ at room temperature, then plasma layer was isolated according to supplier's protocol. The PBMC pellets were resuspended in RPMI to $1 \times 10^{6}$ cells in $0.2 \mathrm{ml}$ and incubated overnight with $10 \mu \mathrm{g} / \mathrm{ml}$ of lipopolysaccharide (LPS) from Pseudomonas aeruginosa. Evoked cytokine responses in conditioned media were determined by multiplexed immunoassay. For the treatment of human PBMCs with LT, $1 \times 10^{6}$ cells in $0.2 \mathrm{ml}$ RPMI medium were incubated for $18 \mathrm{~h}$ with $10 \mu \mathrm{g} / \mathrm{ml}$ LPS (control), LPS and LT $(10 \mu \mathrm{g} / \mathrm{ml})$, or LPS, LT and DEA $(0.1 \%$ or $0.02 \%$ ). Evoked cytokine responses in conditioned media were determined by multiplexed immunoassays.

In vivo studies with $P V L(+)$ MRSA. Animal procurement and housing were performed as described above. For the evaluation of DEA effects on cytokine signaling, mice ( $\mathrm{n}=7$ per group) were injected intraperitoneally (i.p.) with 1) $10^{6} \mathrm{CFU}$ PVL(+) MRSA in culture medium, 2) with PVL(+) MRSA and DEA (50 mg/kg) in vehicle (0.5\% Tween-20 in PBS) and 3) control group (vehicle). The animals were terminated after $24 \mathrm{~h}$ and plasma was isolated for cytokine measurements.

For PVL(+)MRSA survival experiments, mice ( $\mathrm{n}=10$ per group) were randomized into: 1$)$ vehicle control (0.5\% Tween-20 in PBS), 2) $1 \%$ DEA, 3) erythromycin $100 \mathrm{mg} / \mathrm{kg}$, and 4) DEA plus erythromycin. All animals received i.p. injection with $10^{6} \mathrm{CFU}$ PVL(+) MRSA and the treatment .was administered as $3 \times$ daily i.p. injections. The animals were sacrificed after $76 \mathrm{~h}$.

Statistical analysis. Power analysis was performed for all in vitro and in vivo studies that used multiplexed immunoassays. Statistical analysis was done using Student t statistic; $p$-values $<0.05$ were considered significant. All samples/data were included in the analysis. Continuously distributed outcomes were summarized with the mean and standard deviation. Relative values were graphically represented with a heat map. For the analysis of PAMP receptor agonist data, $p$-values for the comparison of DEA-treated groups and untreated controls were calculated for each biomarker using Wilcoxon signed-rank test and the $p$-values were adjusted for multiple comparisons using Benjamini-Hochberg within each column. All treatment groups were contrasted with regard to the mean using analysis of variance and for each biomarker, pairwise comparisons between treatment groups were corrected for multiple testing using the Tukey method. For the entire study, all statistical testing was two-sided with a nominal and experiment-wise significance level of 5\% using SAS Version 9.2. R (SAS Institute Inc., Cary, NC, USA) was used for graphics.

\section{Results}

Azelates were nontoxic to mammalian cells. Assessment of the in silico toxicology (37) of the azelates (Figure 1) predicted no toxicity in mammalian cells. In vitro, the azelates tested at $0.0006 \%$ to $10 \%(\mathrm{w} / \mathrm{v})$ showed no trace of genotoxicity in the Ames test. Given the ubiquity of azelates in mammalian cells and in various foods, we expected the esters to be well-tolerated in our studies. To evaluate toxicity of azelates in mammalian cells, we used two human cell models, PBMCs and EpiDerm tissue, also known generically as a reconstructed human epidermis. EpiDerm is 3dimensional human tissue construct of non-transformed human keratinocytes organized into basal, spinous, and granular layers along a multi-layered stratum corneum with an air-liquid interface. These tissues also exhibit in vivo-like morphological and growth characteristics that allow topical application to the surface of the tissue which mimics the route of human exposure. EpiDerm allows for the evaluation of topically applied compounds, chemicals, cosmetic or personal care product ingredients and final formulations. EpiDerm is the gold standard for a broad range of highly predictive applications (38).

At concentrations up to $25 \%$, the azelates did not affect cell proliferation as shown by the MTT and MTS assays or by cell viability assays based on ATP levels in a EpiDerm skin model and human PBMCs. When the EpiDerm tissues were exposed to $0.1 \%$ croton oil irritant, treatment with $25 \%$ DEA nullified the irritant toxicity in proliferation and viability assays, and protected tissue integrity as evaluated by a microscopic inspection.

Azelates modulated plasma membrane fluidity. We compared the effects of the azelates versus cholesterol as a putative membrane stabilizer (39) on membrane fluidity in human PBMCs using lipophilic pyrene probes (40). These probes diffuse in lipid bilayers and can form fluorescent excimers whose formation depends on plasma membrane fluidity so the fluorescent signal is higher in more fluid membranes. When compared to cholesterol, the membrane fluidizing effects of the azelates increased with increasing alcohol chain length with the exception of dicyclohexyl azelate (Figure 2). The changes in membrane fluidity were concentration-dependent but the effects were clearly Ushaped. A representative example of DEA is shown in the inset in Figure 2. At the lowest tested concentration of 100 $\mathrm{nM}$ (corresponding to $0.0001 \% \mathrm{w} / \mathrm{v}$ ), DEA evidenced nearly 2-fold greater fluidizing activity than it did at $10 \mu \mathrm{M}$.

Our results support the notion that azelates may alter the ordering of self-organized membrane microdomains known as lipid rafts (41), and, in consequence, the activities of membrane proteins.

Each of the azelates and azelaic acid produced different and non-equivalent effects on cellular signaling. The observed gradient of plasma membrane fluidizing activity of the azelates in human PBMCs prompted us to explore the biological consequences of this phenomenon. We used large multiplexed immunoassay panels of over 100 markers to study 
1.<smiles>O=C(O)CCCCCCCC(=O)O</smiles>

4.<smiles>CC(C)OC(=O)CCCCCCCC(=O)OC(C)C</smiles>

2.<smiles>COC(=O)CCCCCCCC(=O)OC</smiles>

3.<smiles>CCOC(=O)CCCCCCCC(=O)OCC</smiles>

5.<smiles>CC(C)COC(=O)CCCCCCCC(=O)OCC(C)C</smiles>

6.<smiles>CCCC(C)OC(=O)CCCCCCCC(=O)OC(C)CCC</smiles>

7.<smiles>CCC(C)COC(=O)CCCCCCCCC(=O)OCC(C)CC</smiles>

8.<smiles>CC(C)CCOC(=O)CCCCCCCC(=O)OCCC(C)C</smiles>

9.

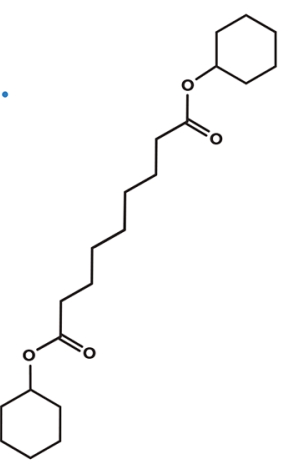

Figure 1. Chemical structures of azelaic acid and azelate acid esters. 1; azelaic acid, 2; dimethyl azelate, 3; diethyl azelate, 4; di-isopropyl azelate, 5; di-isobutyl azelate, 6; di-(1-pentyl) azelate, 7; di-(2-pentyl) azelate, 8; di-(3-pentyl) azelate, 9; dicyclohexyl azelate.

the immunomodulatory effects of the individual azelates in vitro. Queried markers in this study included cytokines, chemokines and growth factors. A term "cytokine" is often used to encompass such a broad range of markers (42) and we use the term in the expansive sense here. We have also compared signaling patterns across treatment groups because multimarker analyses have a far greater informative potential and statistical power than single markers $(36,43)$.

Figure 3 highlights unique cytokine patterns evoked by individual azelates in EpiDerm tissue lysates and conditioned media. In most cases there was a significant or nearly significant down-regulation of cytokines both in conditioned media and in tissue lysates. Interestingly, only DMA upregulated several soluble media markers and the effects of D2PA were quite similar. We also noted marked differences in the signaling patterns evoked by DEA and azelaic acid in the EpiDerm model (data not shown). In particular, DEA and azelaic acid evoked strikingly dissimilar biomarker modulation patterns in human plasmacytoid dendritic cells (Figure 4). Overall, significant differences in activity between individual azelates, DEA, and azelaic acid strongly suggest that the azelates and the parent acid are truly different pharmacological entities. Even though the azelates are metabolized to azelaic acid and the corresponding alcohols over time, the biochemical actions attributable to azelaic acid are very different relative to those of each and every ester.

DEA modulated innate danger signaling from pattern recognition receptors. If our hypothesis that the azelates exert their biological activities via interaction with cell membranes is true, one would expect to see simultaneous effects of a given azelate on many types of receptors, particularly those that form active quaternary complexes composed of two or more subunits.

We investigated this concept in human plasmacytoid dendritic cells, which express a multitude of patternrecognition receptors (PRR) such as pathogen-associated molecular pattern (PAMP) receptors that include Toll-like receptors (TLR), nucleotide oligomerization domain receptors (NOD) and dectin-1 receptors. The TLRs form homo- and hetero- dimeric complexes in the plasma membrane or within endocytic compartments and are involved in signal 


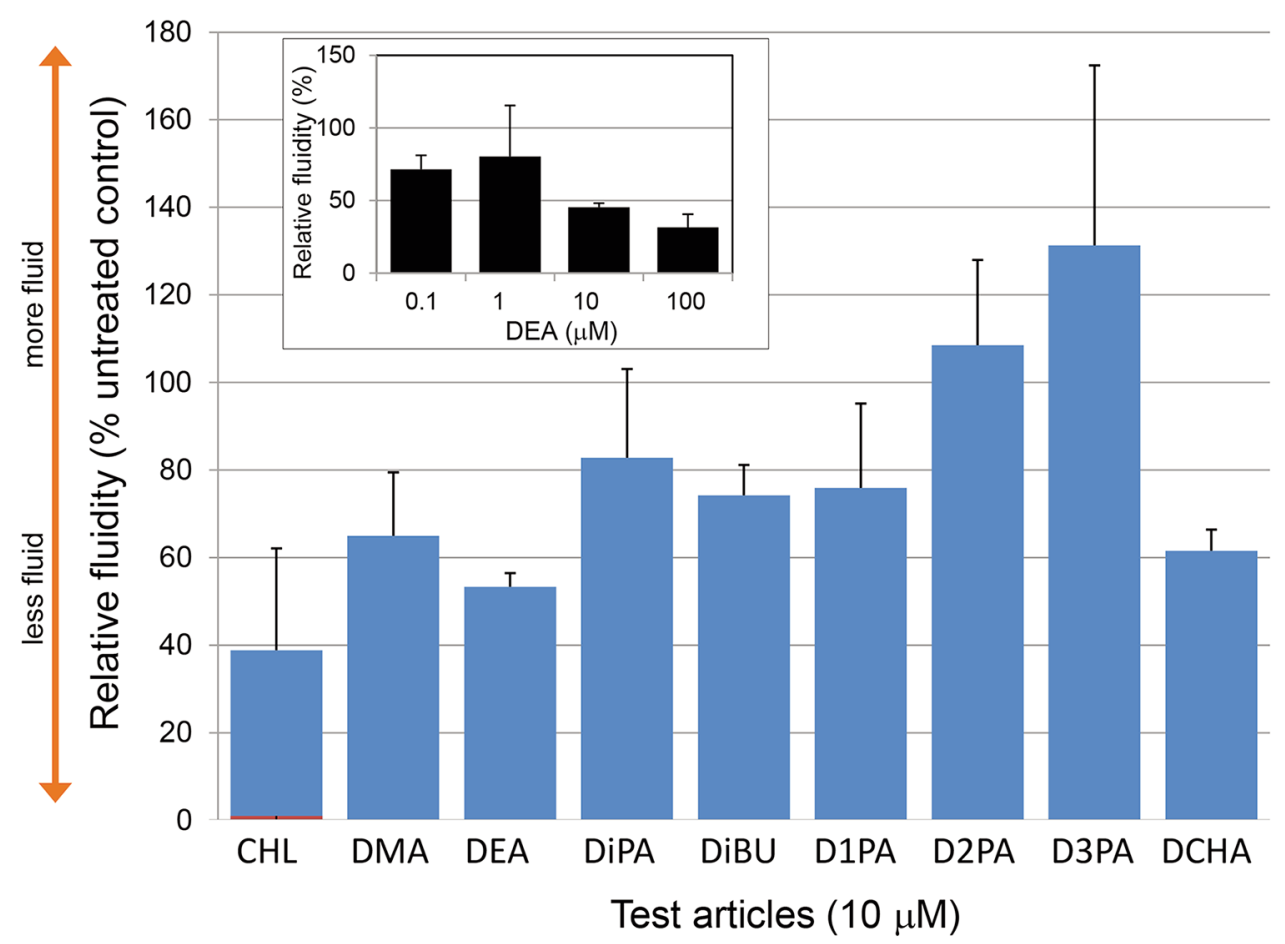

Figure 2. Comparison of cholesterol and azelaic acid ester effects on plasma membrane fluidity in human peripheral blood mononuclear cells. The cells $\left(7 \times 10^{5} / \mathrm{ml}\right.$ ) were treated with cholesterol or azelates (all compounds at $10 \mu \mathrm{M}$ ) for $20 \mathrm{~min}$. Membrane fluidity is expressed as a percentage of untreated control; averages of 3 measurements, error bars with standard deviations. Inset shows the dependence of membrane fluidity on diethyl azelate concentration from 100 to $0.1 \mu \mathrm{M}$. CHL, Cholesterol.

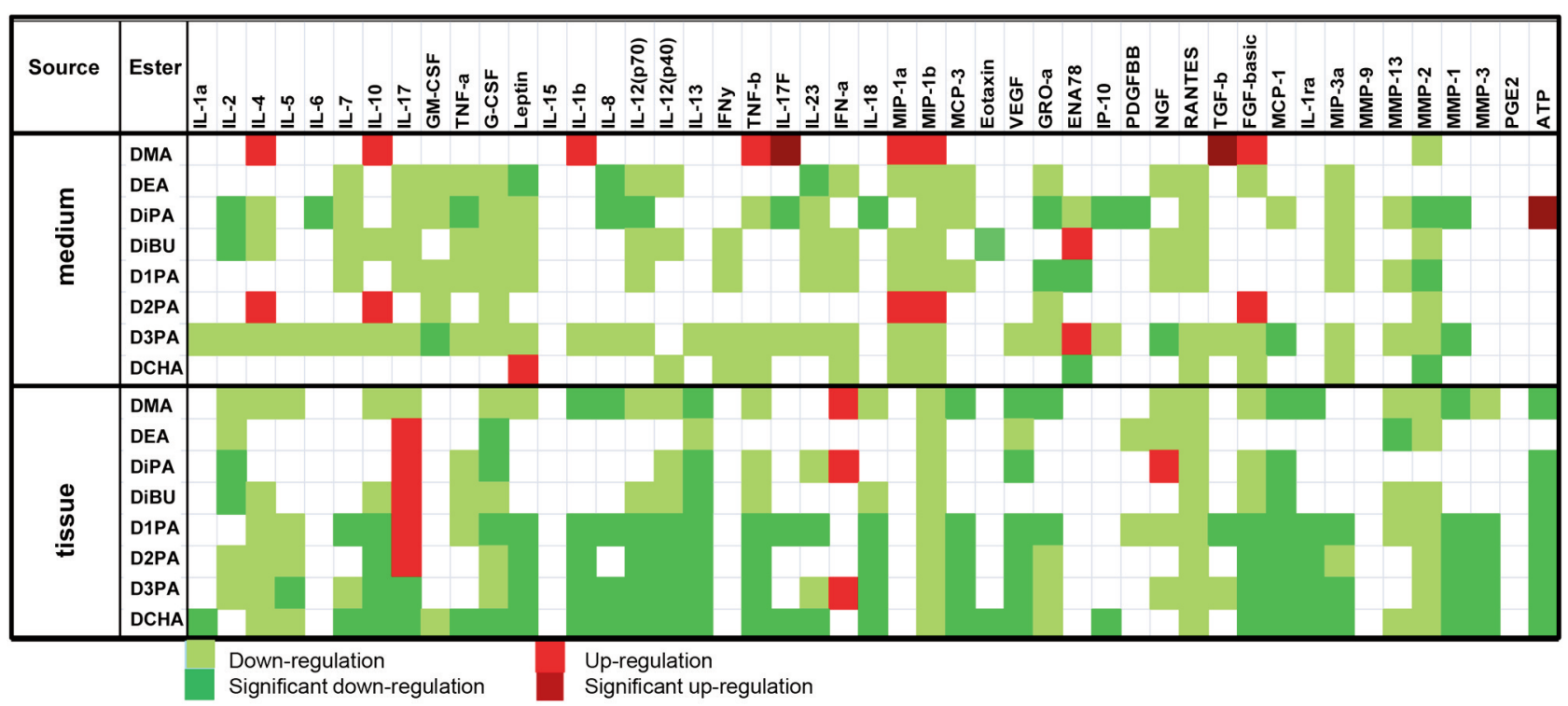

Figure 3. Differences in cell signaling activities of azelaic acid esters in a 3-dimensional EpiDerm human skin model. The EpiDerm tissues were treated with $0.1 \%$ croton oil in the absence or presence of $25 \%$ esters for $18 \mathrm{~h}$. Evoked cytokine responses were measured in tissue lysates and conditioned media using multiplexed immunoassays. Percentage differences in marker expression after treatment with croton oil and the esters were compared to croton oil alone. Red $>2$-fold up-regulation; green $>2$-fold down-regulation. Dark shades of red and green indicate significantly affected markers; $p<0.05$. 


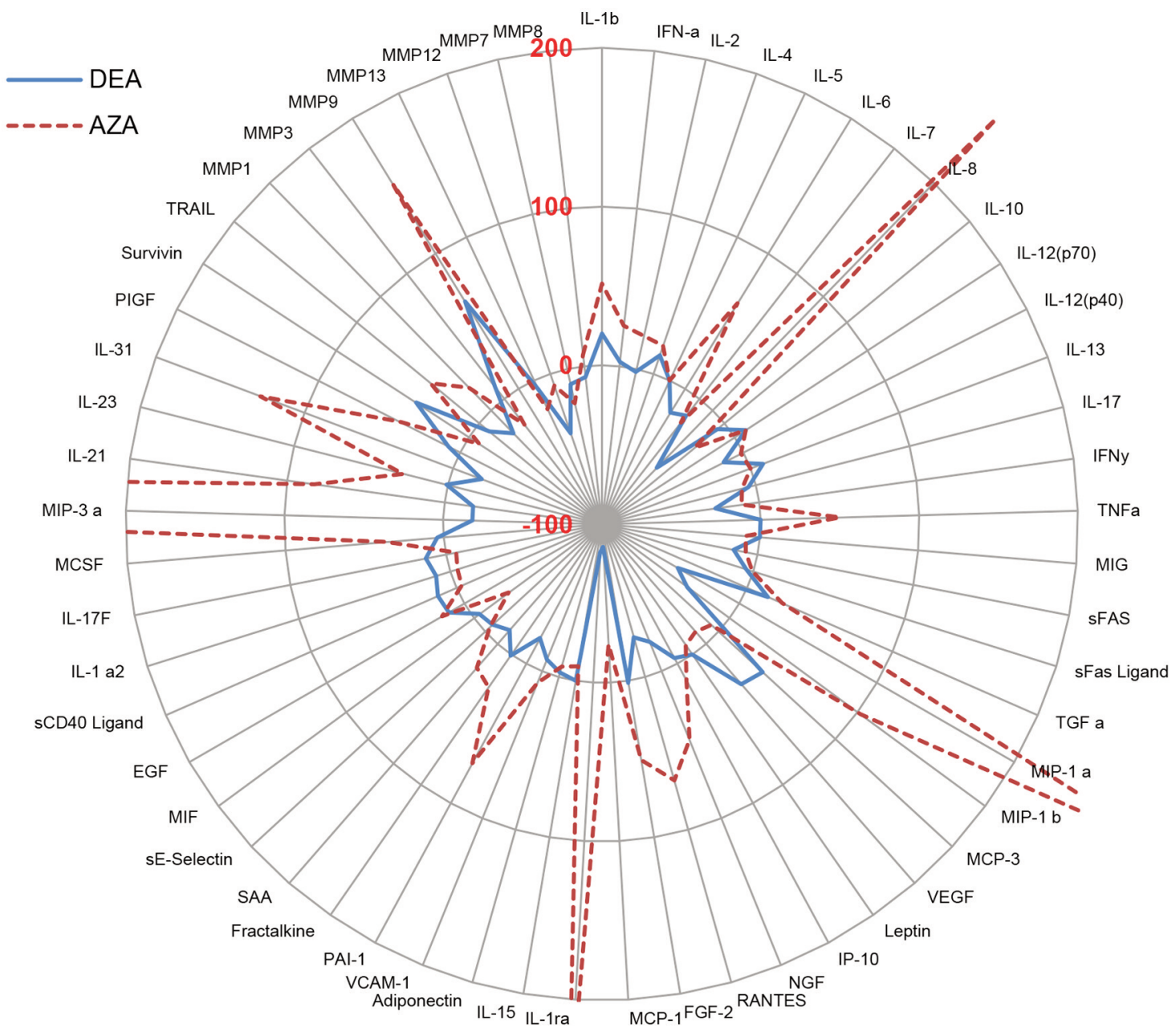

Figure 4. Cytokine signatures of diethyl azelate and azelaic acid in human plasmacytoid dendritic cells. The cells $\left(1.6 \times 10^{5} / \mathrm{ml}\right)$ were treated with diethyl azelate or azelaic acid (0.5\% each) for $18 \mathrm{~h}$ and the levels of cytokines were measured in the cultured media using multiplexed immunoassays. The results are expressed as percentages of controls with numerical values shown on a vertical spoke on the radar plots. The control level is at zero line; values $>0$ indicate biomarker up-regulation and values $<0$ indicate biomarker down-regulation. Blue line; DEA; red line; AZA.

transduction (44-47). TLRs 1, 2, 4, 5 and 6 are localized on the cell surface in the plasma membrane, where they detect extracellular microbial components that come into contact with cells. TLRs 3, 7, 8 and 9 are present in the cell interior in the membranes of endosomes and lysosomes. These TLRs detect RNA and DNA of viral, bacterial and sometimes of the host origin in the form of already internalized and partly broken down fragments (46). The NOD1 and NOD2 receptors are cytosolic monomeric proteins that recognize the presence of bacterial peptidoglycans (48). Dectin-1 is a dimeric C-type lectin receptor that spans the plasma membrane and detects the presence of $\beta$-glucans derived from fungal cell walls (49).

Dendritic cells were stimulated with physiologically relevant concentrations of the 20 PAMP receptor agonists alone or in combination with $0.5 \%$ DEA. We first used extracellular ATP measurements to assess the effects of DEA on cellular signaling induced by the receptor ligands. Extracellular ATP is recognized as a danger signal and ATP release is induced by molecules that might cause damage to the cells $(50,51)$. The results were expressed as a ratio of the levels of ATP secreted from cells treated with DEA plus each of 20 different PAMP receptor agonists to those from cells treated with receptor agonists alone. Except for ieDAP (NOD1 receptor agonist) and murabitide (NOD2 receptor agonist), the ATP ratios measured for the other 18 receptor agonists were all $<1$, indicating that DEA suppressed ATP release (Figure 5). This means that DEA modulated the activity of PAMP receptors and decreased ATP danger signaling from both surface and endosomal/cytoplasmic 


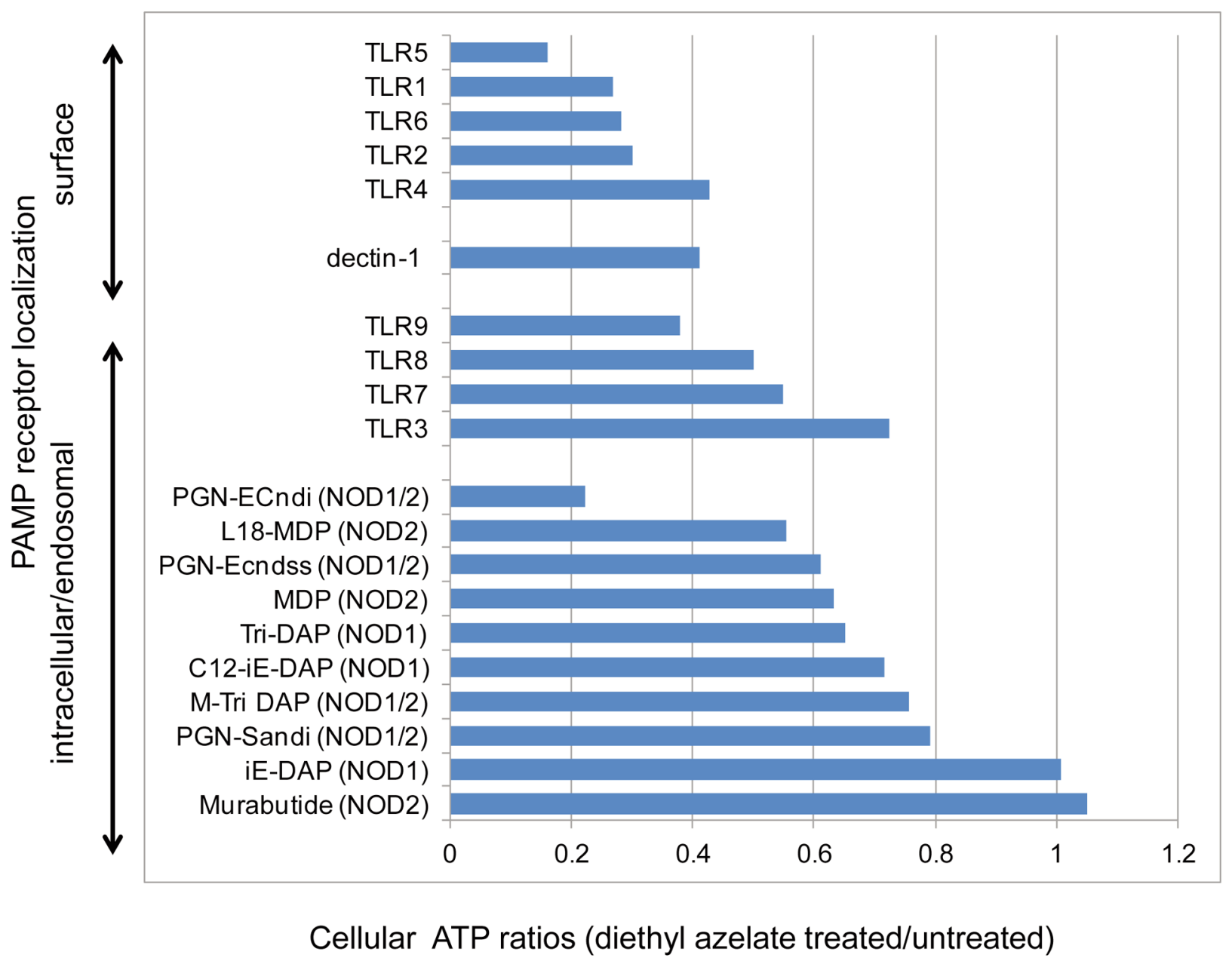

Figure 5. Modulation of ATP release by PAMP receptor agonists alone and in the presence of diethyl azelate (DEA) in human plasmacytoid dendritic cells. The cells $\left(1.6 \times 10^{5}\right.$ cells $\left./ \mathrm{ml}\right)$ were exposed to 20 different PAMP receptor agonists alone, at concentrations within physiological ranges of each agonist, or in the presence of $0.5 \%$ DEA for $24 \mathrm{~h}$. The results are expressed as the ratios of secreted ATP from the cells treated with the PAPM receptor agonists and DEA (treatment groups) to the levels of ATP secreted by the cells treated with the agonists alone (control groups). The agonists are arranged according to their respective receptor localization on the cell surface or inside the cells.

receptors. The effect on the plasma membrane-localized receptors was greater, consistent with the primary activity of DEA at the cell surface and less so on the receptors locate in the interior of the cells. The effects of DEA were also greater for receptors forming multimeric functional assemblies, i.e., TLRs and dectin-1, relative to the monomeric receptors.

DEA modulated cytokine, chemokine and growth receptor signaling from PRRs. The effect of DEA on signaling evoked by the same PAMP receptor agonists was evaluated using multiplex immunoassay of 57 cytokines. DEA treatment affected patterns of secreted markers evoked by all agonists. Representative data for each type of receptor (9 TLRs, 3 NODs, and dectin-1) are shown in Figure 6, Figure 7 and
Figure 8. The effects of DEA treatment on modulation of agonist-evoked signaling from the cell surface receptors TLR1, 2, 4, 5, and 6 are shown in Figure 6A-E. The 5-fold scale for depicting changes in expressed cytokines levels highlights the benefit of DEA treatment on mitigating cytokine storm induced by TLR agonists.

A detailed description of DEA effects on each TLR and on each marker is beyond the scope of this manuscript. A very important observation is that every TLR ligand evoked unique cytokine response patterns with over 10 -fold to several hundred-fold increases of marker levels above the control levels and that DEA in presence of the ligands brought the cytokine levels to the nearly background (vehicle) levels. Presented below is a more detailed analysis of TLR4, which recognizes LPS, a component present in 
many Gram-negative bacteria, some viral proteins and even low density lipoprotein (52). As shown in Figure 6C, stimulation of TLR4 with LPS resulted in significantly elevated levels of multiple markers including 65 -fold increase of interleukin (IL) 12 subunit p40 [IL-12(p40)], macrophage inflammatory protein (MIP)-1 alpha (94-fold), regulated on activation, normal $\mathrm{T}$ cell expressed and secreted protein (RANTES) (93-fold) and MIP-3 alpha (89fold). DEA brought these and other markers to the nearly control levels.

Figure 7A-F presents the analogous data for TLRs 3, 7, 8, and 9. Excepting IP-10 (17.5-fold increase with TLR3 agonist; Figure 7A) and matrix metalloproteinase (MMP) MMP-9 (11.3-fold increase with TLR9 agonist; Figure 7C) that were normalized to the vehicle levels by the addition of DEA, cytokine signaling from TLRs 3, 7, and 9 stimulation was relatively mild. A completely different picture emerged from TLR8 agonist and its modulation by DEA (Figure 7DF). While TLR 8 also recognizes bacterial RNA degradation products, in this study we stimulated this receptor with a single strand RNA (ssRNA) representing RNA viruses. Human diseases caused by RNA viruses include the common cold, influenza, HIV, HCV, hepatitis C, hepatitis E, West Nile fever, Ebola virus disease, rabies, polio and measles, and coronavirus disease such as SARS, MERS and COVID-19 $(53,54)$. However, development of antiviral drugs to prevent or treat human coronavirus infections has not been realized.

The magnitude of cytokine signals from stimulation of TRL8 with ssRNA was exceptionally high when compared to other PAMP receptors, an effect which is better appreciated when the scale is expanded from 5-fold (Figure 7D) to 100-fold (Figure 7E-F). DEA treatment lowered the levels of almost all measured inflammatory markers. The most affected markers (with the numbers in parenthesis indicating the $n$-fold change of marker levels before DEA and after DEA treatment, respectively) were IL-1b (66 and 23), IL-6 (71 and 14), IL-12p70 (466 and 3), IL-12p40 (215 and 47), tumor necrosis factor (TNF) alpha (527 and 23), MIP-1a (100 and 33), interferon gamma-induced protein 10 (IP-10), (1710 and 295), RANTES (218 and 15) and MIP3a (40 and 7).

NOD receptor signaling data were qualitatively similar for all examined ligands. As shown in Figure 8, signaling patterns of the representative NOD receptor agonists were qualitatively similar to each other without and with DEA treatment. The most significantly affected markers were MIP1a, RANTES, and MMP-12. Dectin-1 signaling modulation resembled the NOD patterns. The most prominent markers affected by DEA included TNF alpha, MIP-1a, IL-31 and MMP-9.

The global effects of DEA on TLR and NOD receptor signaling can be appreciated by the dendrograms and heat maps in Figure 9. For TRLs taken as a group, the $p$ values for all biomarkers were highly significant (from 0.00214 to $2.17 \mathrm{E}-5)$. The degree of separation represented by the dendrogram branches was significantly reduced upon treatment (Figure 9A and B). The patterns of TLR clustering correlated with the cellular localization of individual TLRs. In the absence of DEA, the dendrogram resembled the phylogenetic tree of TLRs (55). With DEA treatment, cell surface receptors TLRs 8, 9 and 3 clustered into large branches. The intracellular TLRs 6, 5, 2 and 4 clustered into closely related branches separated from the cell surface TLR cluster. Corresponding data on DEA effects on histograms are shown in Figure 9C-D. The effects of DEA on NOD receptor signaling were significant with $p$-values of 0.03 for all markers and the shape of the dendrogram was similar in the presence or absence of DEA as shown by two arms in Figure 9E.

DEA abolished assembly of cholera toxin B subunit membrane attack complexes on PBMC plasma membranes. The general activity of DEA in modulation of activities of endogenous mono- and multimeric proteins prompted us to investigate DEA modulation of exogenous multimeric proteins. As a probe, we chose cholera toxin, a multimeric $\mathrm{AB}_{5}$ toxin produced by Vibrio cholerae. The $\mathrm{B}$ subunit of the toxin binds to cell surface GM1 ganglioside receptors, which are also implicated in pain signaling (56). The receptor bound $\mathrm{B}$ subunits are localized to membrane microdomains referred to as lipid rafts, where they form pentameric membrane attack complexes. The A subunit of the toxin binds to the pentamer of membrane receptor bound $\mathrm{B}$ subunits and the complex is internalized via endocytosis releasing the toxic A subunit into the cytoplasm (57). Cholera toxin B subunits interact with lipid raft localized receptors whose stability is necessary for toxin activity (58).

To examine the effect of DEA on the formation of the membrane attack complex, we exposed human PBMCs to fluorescently labeled cholera toxin B subunit with or without treatment with DEA. Phase contrast microscopy (Figure 10A) showed individual untreated cells, while the corresponding fluorescent micrographs of the cells (Figure 10C) showed foci of enhanced fluorescence allowing the visualization of assembled membrane attack complexes. More specifically, discrete clusters of fluorescent intensity of the labeled B subunit appeared on the plasma membrane of the cells, in consistence with the literature data (59). On the other hand, DEA-treated cells (phase contrast image in Figure 10B) lacked foci of labeled B subunit on their surfaces but showed faint diffuse fluorescence spread evenly over the surfaces of the plasma membranes (Figure 10D). Decreased numbers of the DEA-treated PBMCs likely resulted from limited adhesion of the cells to glass slide surfaces due to membrane fluidization caused by DEA treatment. Overall, these results suggest that DEA 

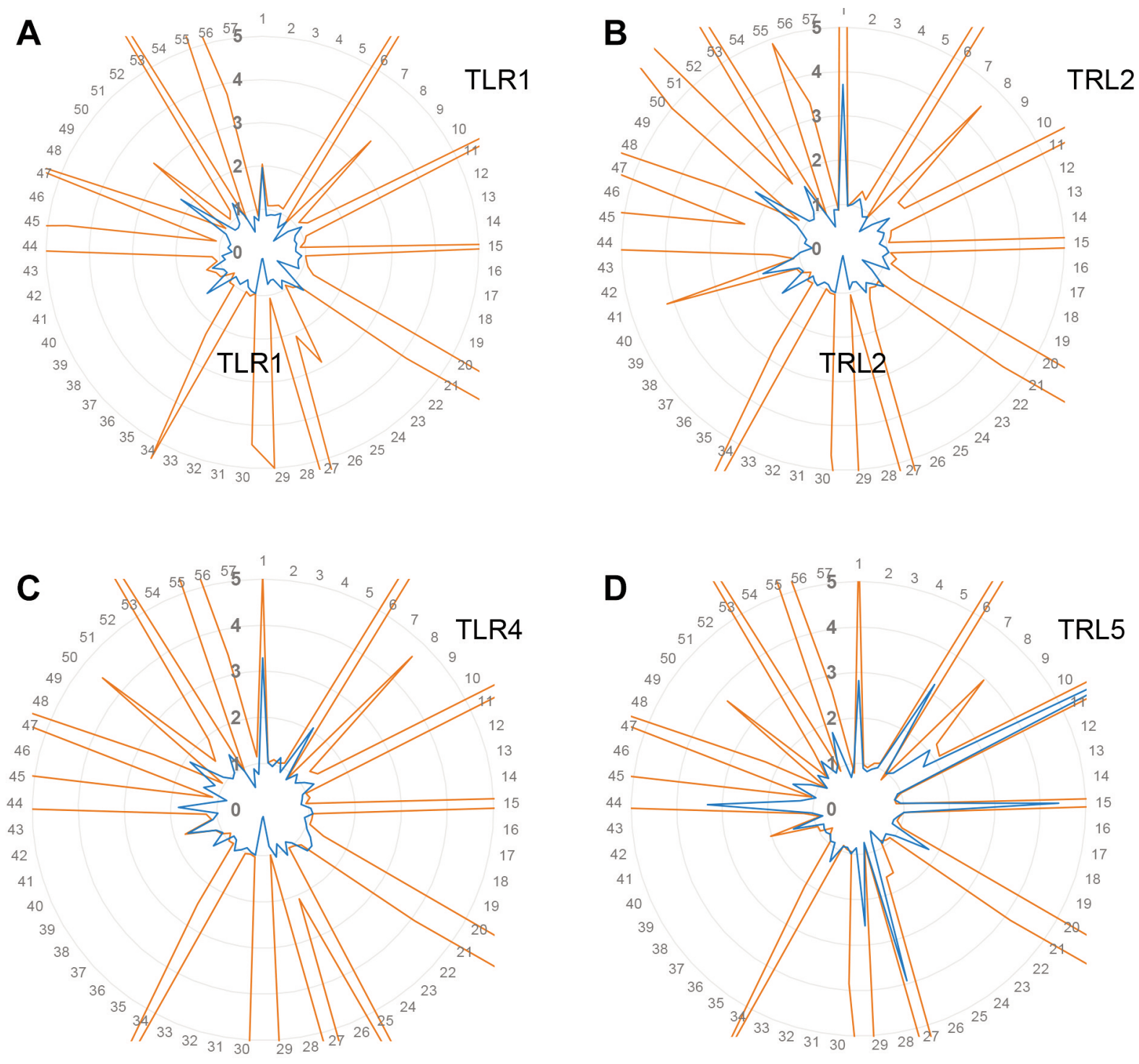

Figure 6. Continued

disrupted B subunit pentamer formation and/or B subunit to GM1 receptor binding. Since the localized binding of cholera toxin B subunit on the plasma membrane is a standard method to visualize lipid rafts (59), the results also suggest that DEA interferes with organization of plasma membrane microdomains.

DEA counteracted immunosuppression by anthrax lethal toxin in vivo. The toxin of Bacillus anthracis is a classic example of a bacterial virulence factor that suppresses the immune responses of the infected host (60). Anthrax toxin is an A/B type toxin and is composed of the cell-binding PA, and two enzymes, EF and LF that are non-toxic by themselves. EF and LF associate with receptor bound PA to form a heptamer or octamer, and are internalized by a cell they turn into active toxins; edema toxin (ET) or LT, respectively. LT inhibits adaptive immune responses by proteolysis of mitogen-activated protein kinase kinase. EF is an adenylate cyclase which increases cellular cAMP and disrupts cellular water homeostasis. PA-mediated translocation of EF and LF into the cells disrupts immune cell signaling and migration, and induces the lysis of macrophages $(61,62)$. Therapeutic interventions are limited to antibiotics and antibodies to protective antigen. Treatment must be started almost very soon after the exposure $(63,64)$. The immunological manifestations of anthrax infection can 


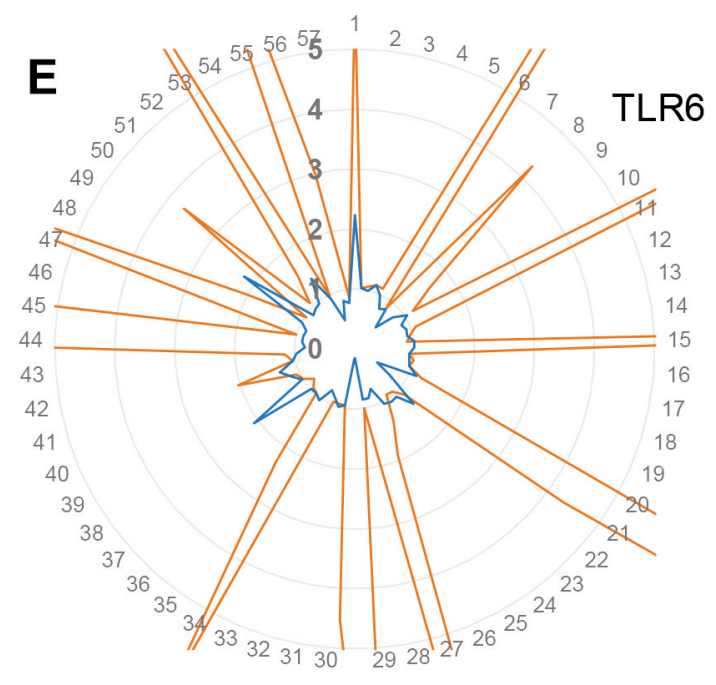

Figure 6. Modulation of cytokine release by TLR1, TLR2, TLR4, TLR 5, and TLR6 agonists alone and in the presence of diethyl azelate in human plasmacytoid dendritic cells. The cells $\left(1.6 \times 10^{5} / \mathrm{ml}\right)$ were exposed to the following receptor agonists: TLR1 (A), TLR2 (B), TLR4 (C), TLR5 (D), and TLR6 (E), either alone at the concentrations within physiological ranges of each agonist or in the presence of $0.5 \%$ diethyl azelate for $24 \mathrm{~h}$. The following cytokines were measured using multiplexed immunoassays: 1 ; IL-1b, 2; interferon (IFN) alpha, 3; IL2, 4; IL-4. 5; IL-5. 6;IL-6, 7;IL-7, 8; IL-8. 9;IL-10, 10;IL-12 p70, 11; IL-12 p40, 12; IL-13, 13; IL-17, 14; IFN gamma, 15; TNF alpha, 16; macrophage induced protein (MIG), 17; soluble Fas cell surface death receptor (sFAS), 18; sFAS ligand, 19; transforming growth factor (TGF) alpha, 20; MIP-1 alpha, 21; MIP-1 beta, 22; monocyte chemoattractant protein (MCP) 3, 23; vascular endothelial growth factor (VEGF), 24; leptin, 25; IP-10, 26; nerve growth factor (NGF), 27: RANTES, 28; fibroblast growth factor (FGF) basic, 29; monocyte chemoattractant protein $(M C P)$ 1, 30; IL-1 receptor agonist, 31; IL-15, 32; adiponectin. 33; VCAM-1, 34; PAI-1, 35; fractalkine, 36; SAA, 37; sE-selectin, 38; MIF. 39; EGF, 40; sCD40 ligand, 41; IL-1 alpha2, 42; IL-17F, 43; MCSF ; 44; MIP-3 alpha, 45; IL-21, 46; IL-23, 47; IL-31, 48; PIGF, 49; survivin, 50; TRAIL, 51; MMP-1, 52; MMP-3, 53; MMP9, 54; MMP-13, 55; MMP-12, 56; MMP-7. 57; MMP-8. The results are presented as the ratios of marker levels measured in the cells treated with receptor agonists alone compared to the vehicle (control group, red line) or with the receptor agonists plus DEA compared to the vehicle (treatment group, blue line).

be mimicked in model systems (65) whereby immune cells exposed to LT lose the ability to release inflammatory cytokines in response to stimulation with LPS.

In this work, we treated mice either with non-lethal dose of LT alone or with LT plus a single i.v. dose of DEA (50 $\mathrm{mg} / \mathrm{kg}$ ). As shown in Figure 11A, DEA treatment preserved the LPS stimulated cytokine release in plasma. PBMCs from LT intoxicated mice treated with DEA released significantly higher quantities of cytokines, and the effect was even more dramatic after LPS and DEA stimulation.

Clearly the exposure to LT was immunotoxic as it strongly suppressed cytokine release from PBMCs in ex vivo culture.
DEA treatment of animals in vivo largely relieved immunosuppression in PBMCs as evidenced by elevated cytokine signaling. Furthermore, DEA treatment in vivo reversed LT induced immunosuppression as highlighted by LPS challenge. These data support our hypothesis that DEA disrupts the formation of the multimeric PA complex on the plasma membrane and prevents cell entry of LF.

DEA countered the action of anthrax lethal toxin activity in human PBMCs. Given demonstration of anti-anthrax DEA activity in vivo, we investigated if DEA has a similar activity in human PBMCs. We compared cytokine signaling in cells incubated for $18 \mathrm{~h}$ with $0.5 \%$ DEA in the presence of LT and LPS (both at $10 \mu \mathrm{g} / \mathrm{ml}$ ) to the cells treated with LT and LPS in the absence of DEA (Figure 11B). The results are presented in the format of volcano plots that combine treatment effect as $n$-fold changes and statistical significance of the change. Figure 11B shows that DEA largely upregulated cytokine secretion that was otherwise suppressed by the LT. Highly significant down-regulation of cytokines such as IL-6, IP-10, and VEGF-A also indicated beneficial effect of DEA. On the other hand, a control experiment (Figure 11C) showed that DEA by itself had a minimal effect on cytokine release. Overall, the results suggest that DEA exerted chemoprotective activity against LT induced immunosuppression in human PBMCs.

DEA inhibited virulence factors multidrug resistant Staphylococcus aureus in human PBMCs and in an in vivo model of bacterial sepsis. Bacterial sepsis kills more people than lung cancer (66). A common pathogen in sepsis, Staphylococcus aureus, in addition to inducing a cytokine storm, causes intestinal epithelium destruction and complete degradation of internal organs. It is suspected that the host response to $S$. aureus is mediated by PAMP signaling (67). Sepsis resulting from drug resistant bacterial strains is most difficult to control. A notorious example is a highly virulent methicillin-resistant $S$. aureus strain PVL(+)MRSA that elaborates various toxins including the multimeric pore forming toxin Panton-Valentine leukocidin. Cytokine storm in bacterial sepsis includes a release of an array of inflammatory cytokines $(68,69)$ combined with impaired glucose tolerance (70). Curiously, adipose-derived hormone leptin becomes a pathogen in sepsis and exacerbates sepsismediated morbidity and mortality (71).

Antibacterial activity of topical azelaic acid and some azelates have been described in terms of their direct killing of bacteria (72). However, since we observed immune-biological activity of azelates at much lower concentrations we suspected that the previously documented anti-pathogen activities of azelates may not be solely due to their bacteriocidal activities. We used PVL(+)MRSA to test the efficacy of DEA in a multidrug were drug resistant bacterial model. In an in vitro 

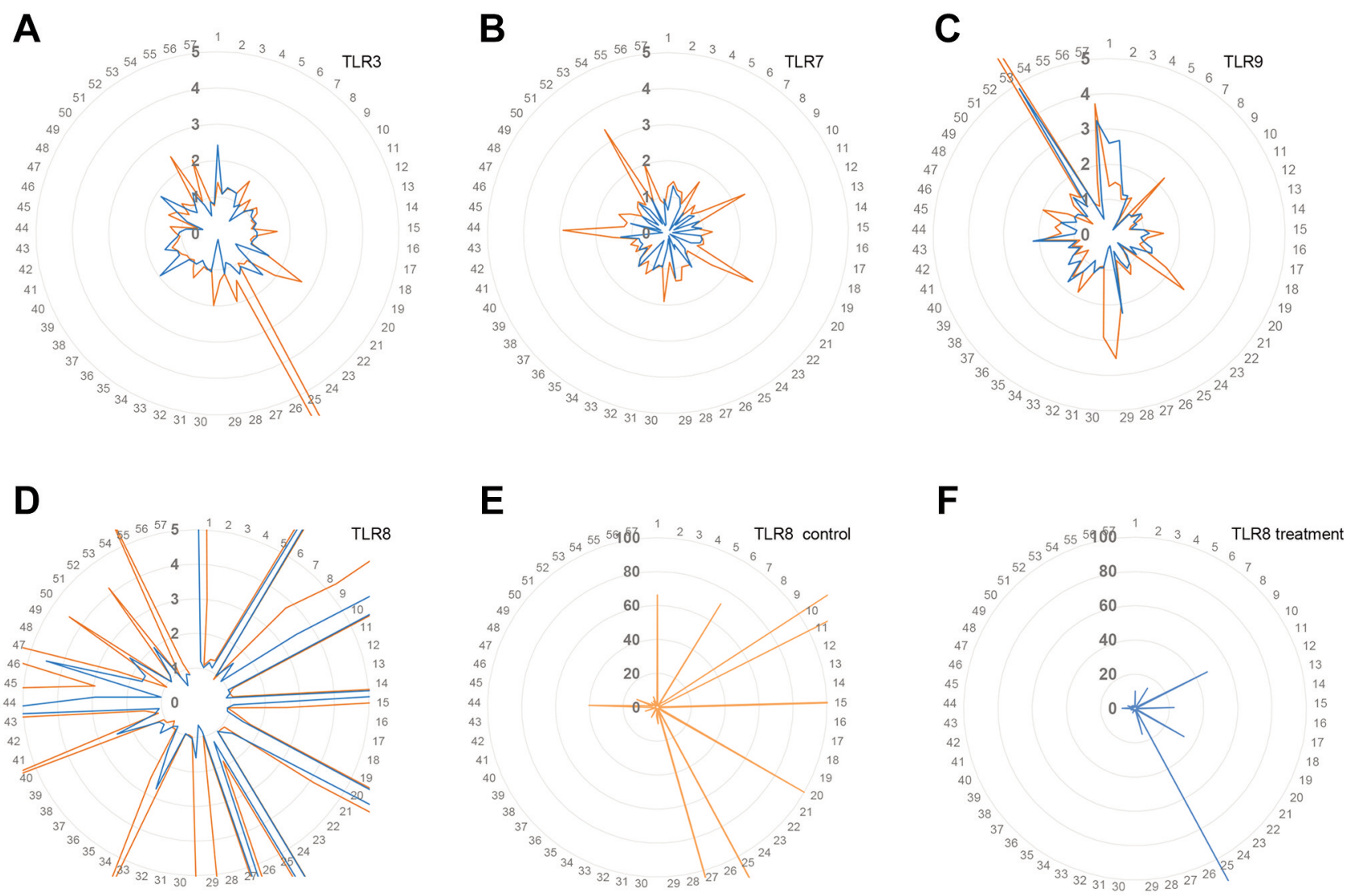

Figure 7. Modulation of cytokine release by TLR3, TLR7, TLR 8, and TLT9 agonists alone and in the presence of diethyl azelate in human plasmacytoid dendritic cells. The cells $\left(1.6 \times 10^{5} / \mathrm{ml}\right)$ were exposed to the receptor agonists within physiological ranges of each agonist either alone or in the presence of $0.5 \%$ diethyl azelate (DEA) for $24 \mathrm{~h}$. TLR3 (A), TLR7 (B), TLR9 (C), TLR8 (D; all treatment and control groups), TLR8 (E; control group, expanded scale), TLR8 (F; treatment group, expanded scale). The cytokine panel was as in the legend to Figure 6. Red lines=control groups, no DEA, blue lines=DEA treatment groups.

experiment lasting 63 days, 5\% DEA completely eradicated the growth for PVL(+)MRSA. EpiDerm tissues exposed to $25 \%$ DEA protected against the damage caused by PVL(+)MRSA lysate (data not shown). When we compared levels of cytokines in conditioned media from EpiDerm tissues exposed to the bacterial lysate alone or the lysate in the presence of DEA, we found that DEA significantly decreased levels of leptin in cultured media as well as IL-1 alpha, IL-1 beta, and MIF in tissue lysates (Figure 12A).

In an in vivo pilot experiment, mice $(n=7$ per treatment group) were injected intraperitoneally with $3 \times 10^{9} \mathrm{CFU}$ PVL(+) MRSA either alone or with PVL(+) MRSA and i.v. DEA $(50 \mathrm{mg} / \mathrm{kg})$ and the plasma was isolated after $24 \mathrm{~h}$. In this short-term experiment neither treatment significantly affected cytokine signaling (data not shown). To investigate if DEA could rescue animals from PVL(+) MRSA infection, we conducted a longer-term study (Figure 12B). The results are representative of two independent experiments $(n=10$ animals per group). DEA alone increased the survival relative to untreated controls ( $75 \%$ versus $55 \%$, respectively) but the effect was not statistically significant. DEA in combination with erythromycin resulted in $100 \%$ survival $(p=0.0149)$. As shown in Figure 12C, even as a monotherapy, DEA prevented intestinal hemorrhages and supported internal organ integrity and had no apparent adverse effects. In contrast, the surviving untreated controls suffered extensive internal organ damage that fitted reported description of the deleterious consequences of sepsis on the body (67).

\section{Discussion}

Immediate implications: the mechanism of action of azelates. Our results show that azelaic acid esters are pharmacologically active and that each possesses unique properties. These pharmacological effects are distinctly different from those of the parent compound. DEA showed a broad range of activities that included suppression of cellular signaling induced by chemical irritants and PAMP 

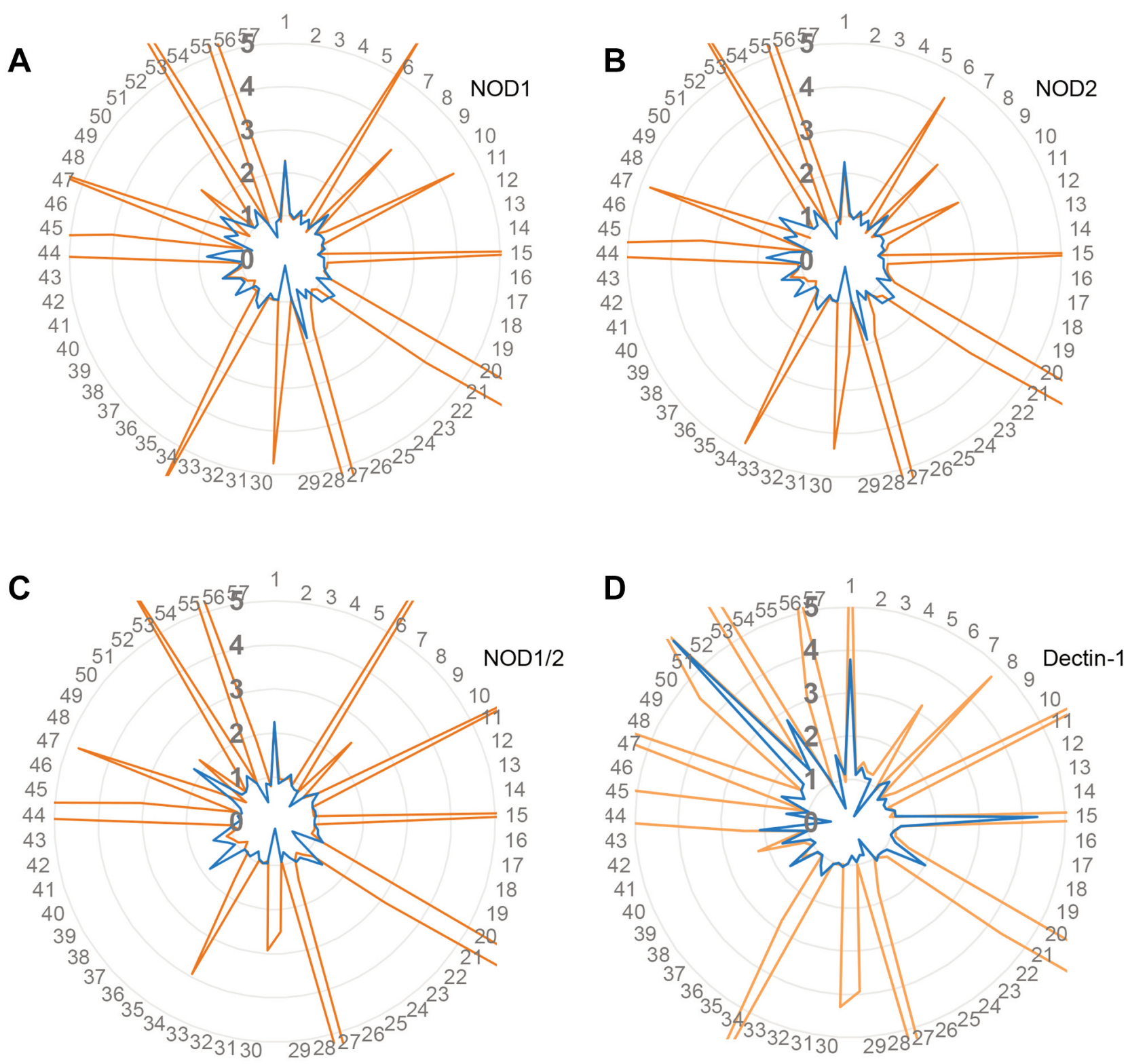

Figure 8. Modulation of cytokine release by representative NOD1, NOD2, NOD1/2 and dectin-1 receptor agonists alone and in the presence of diethyl azelate (DEA) in human plasmacytoid dendritic cells. The cells $\left(1.6 \times 10^{5} / \mathrm{ml}\right)$ were exposed to 20 different PAMP receptor agonists alone at the concentrations within physiological ranges of each agonist or in the presence of $0.5 \%$ DEA for $24 \mathrm{~h}$. The following receptor agonists were used: NOD1 (A), NOD2 (B), NOD1/2 (C), dectin-1 (D). Red lines=control groups, blue lines=DEA treatment groups. The cytokine panel was as in the legend to Figure 6.

receptor ligands. DEA also counteracted the effects of bacterial toxins in vitro and in vivo and modulated activities of membrane proteins with effects seen for proteins inside and outside target cells.

The diversity of the observed biological effects can be explained by the hypothesis that azelates affect cellular signaling via reversible alteration of plasma membrane fluidity. To answer the question of how the azelates mitigate pathological signaling and normalize the cellular responses, we have considered a few scenarios. One possibility is that the azelates simply diffuse into the membrane, change membrane fluidity and affect the activities of integral membrane and membrane-associated proteins involved in intra- and inter- cellular signaling (Figure 13). 

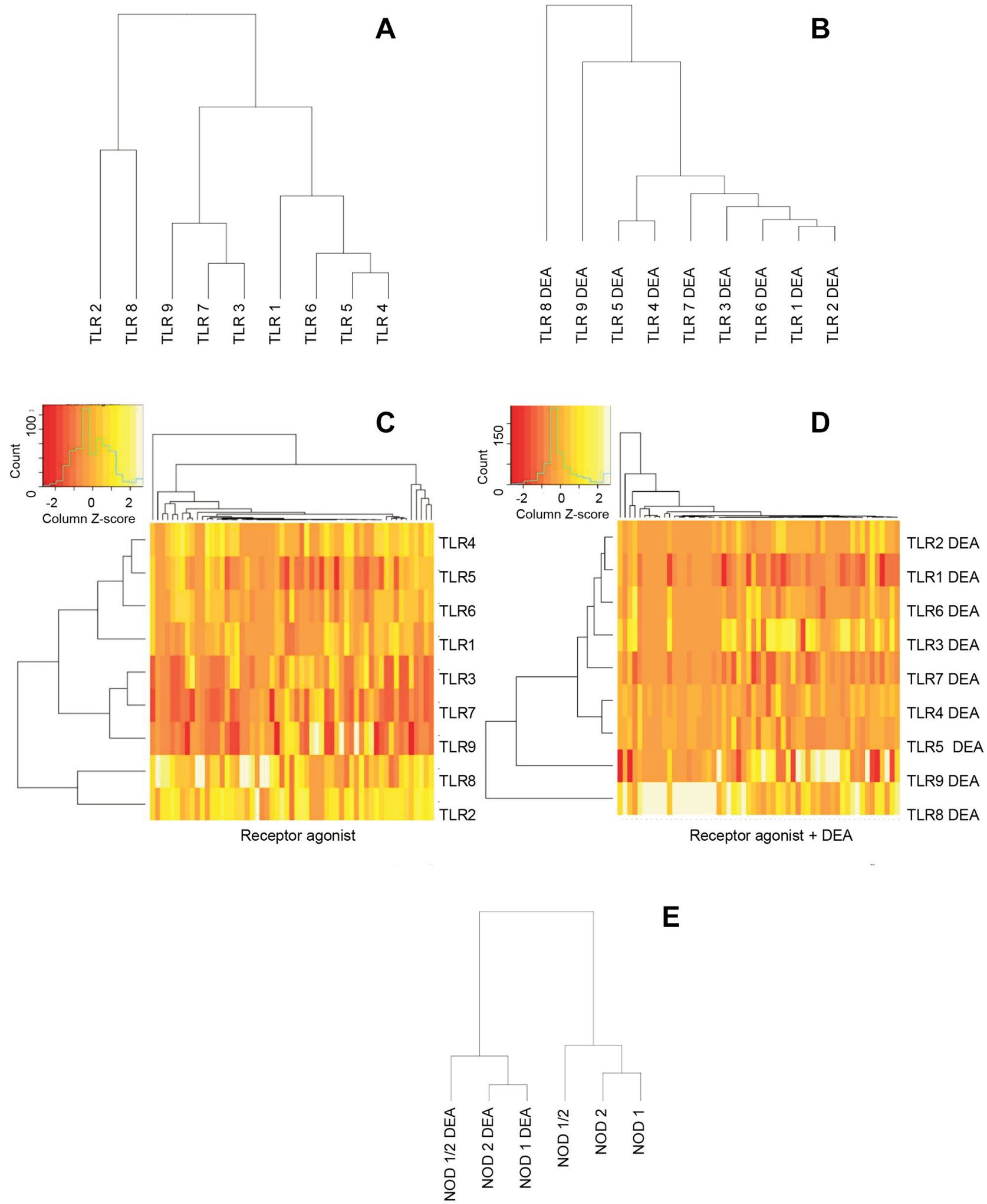

Figure 9. Dendrogram and heat maps summary of cytokine modulating effects of diethyl azelate on TRL and NOD receptors in human plasmacytoid dendritic cells. Dendrogram for the TLR receptor agonists alone $(A)$, the agonists and DEA (B), and corresponding heat maps $(C$ and $D$, respectively). (E) Histogram for representative NOD receptor agonists, NOD1, NOD2, NOD1/2. Data are representative of two independent experiments. 

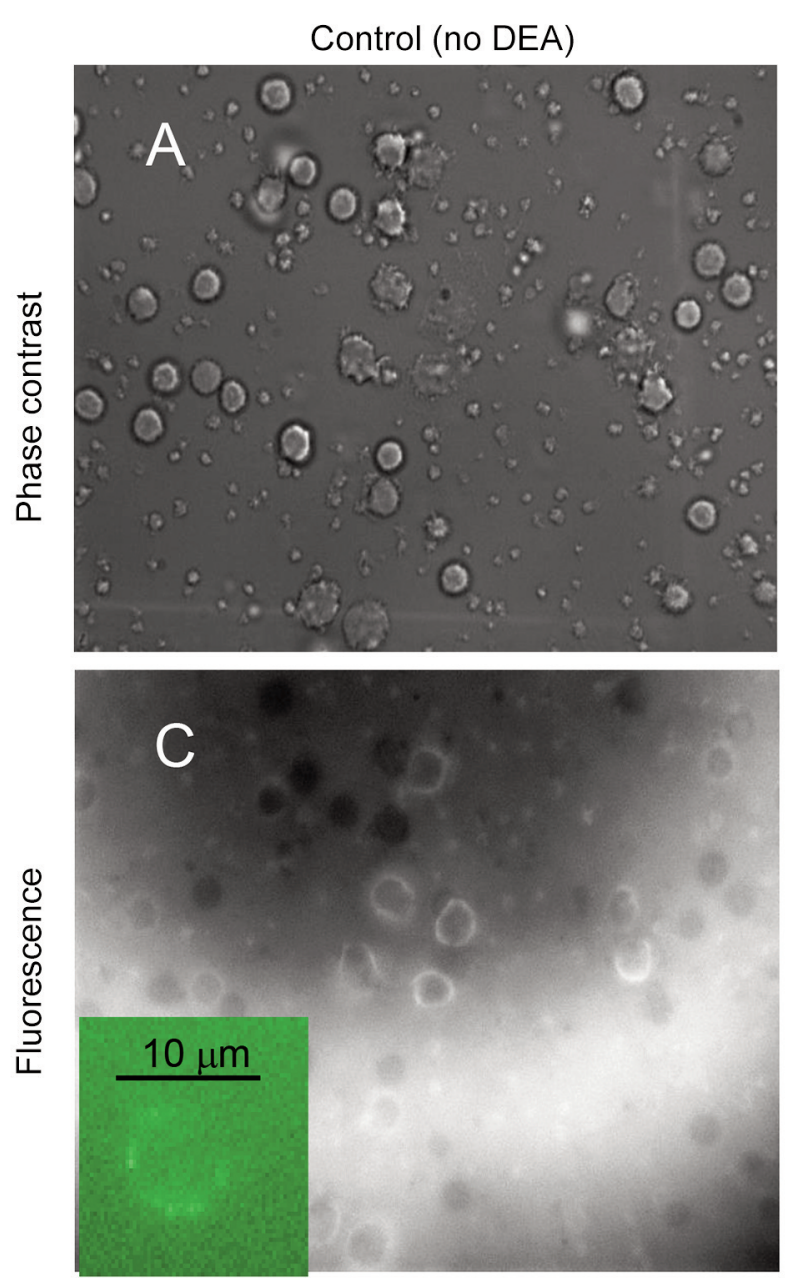
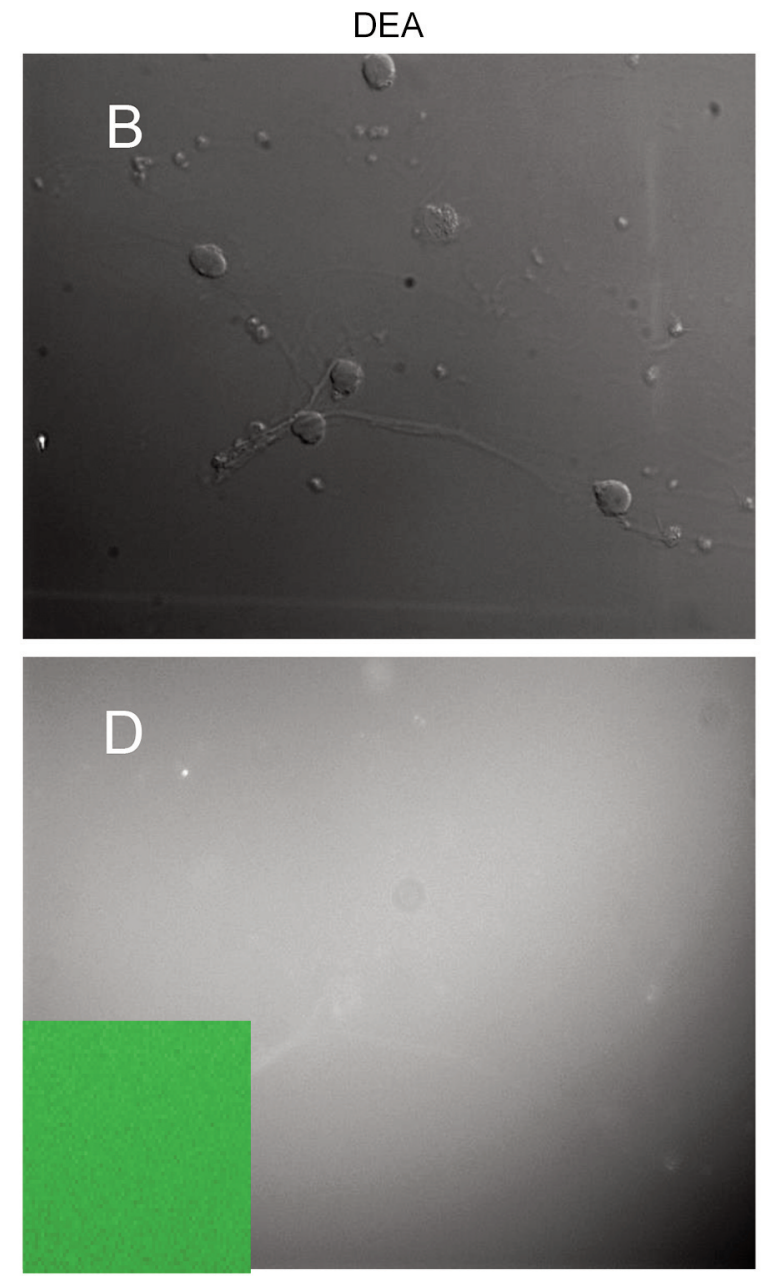

Figure 10. Diethyl azelate interfered with cholera toxin assembly in plasma membrane of human peripheral blood mononuclear cells. Human peripheral blood mononuclear cells (PBMCs) either in the absence or in the presence of $0.5 \%$ diethyl azelate (DEA) were labeled with the fluorescent cholera toxin subunit B (CT-B) conjugated and cross-linked with the anti-CT-B antibody. Lipid rafts were visualized using Vybrant Alexa Fluor 488. Phase contrast $(A, B)$ and fluorescence $(C, D)$ images are representative of two independent experiments with quadruplicate repeats. A scale bar in panel $C$ inset corresponds to $10 \mu \mathrm{m}$.

Our previous data on the inverted U-shaped dose response curve induced by DEA $(32,33)$ suggest that more is not always better and that there is an optimal range of fluidity with undesirable responses being realized outside this optimum fluidity range. Another example of non-linear dose effects is the effect of non-aliphatic alcohols that alter membrane fluidity and alter ligand binding to brain receptors (73). Membrane fluidizers such as propanol and butanol affect the number of chemotactic factor receptors (74). Solvent polarity is known to affect enzymatic activity (75) and ligand-receptor interactions (76). Conceivably, the amphiphilic azelates (based on their octanol: water partitioning values; unpublished data) may interfere with ligand binding to receptors or enzyme-substrate interactions.
Membrane charge affected by membrane composition and membrane potential plays a vital role in cellular signaling (77). Further, the plasma membrane interactions with the cytoskeleton modulate the mobility of proteins and lipids in the membrane and are highly relevant for receptor-mediated signaling, especially for immunoreceptors (78). All these processes may be affected by the azelates.

Azelates may also nonspecifically modulate ligandreceptor or enzyme-substrate interactions through their effects on tertiary protein structures affecting protein conformations, and quaternary protein structures such as those between subunits of multimeric proteins or other protein complexes. Sterols and dietary lipids have been proposed to affect the receptor-mediated cellular immune responses $(79,80)$. Membrane fluidizers can affect the 

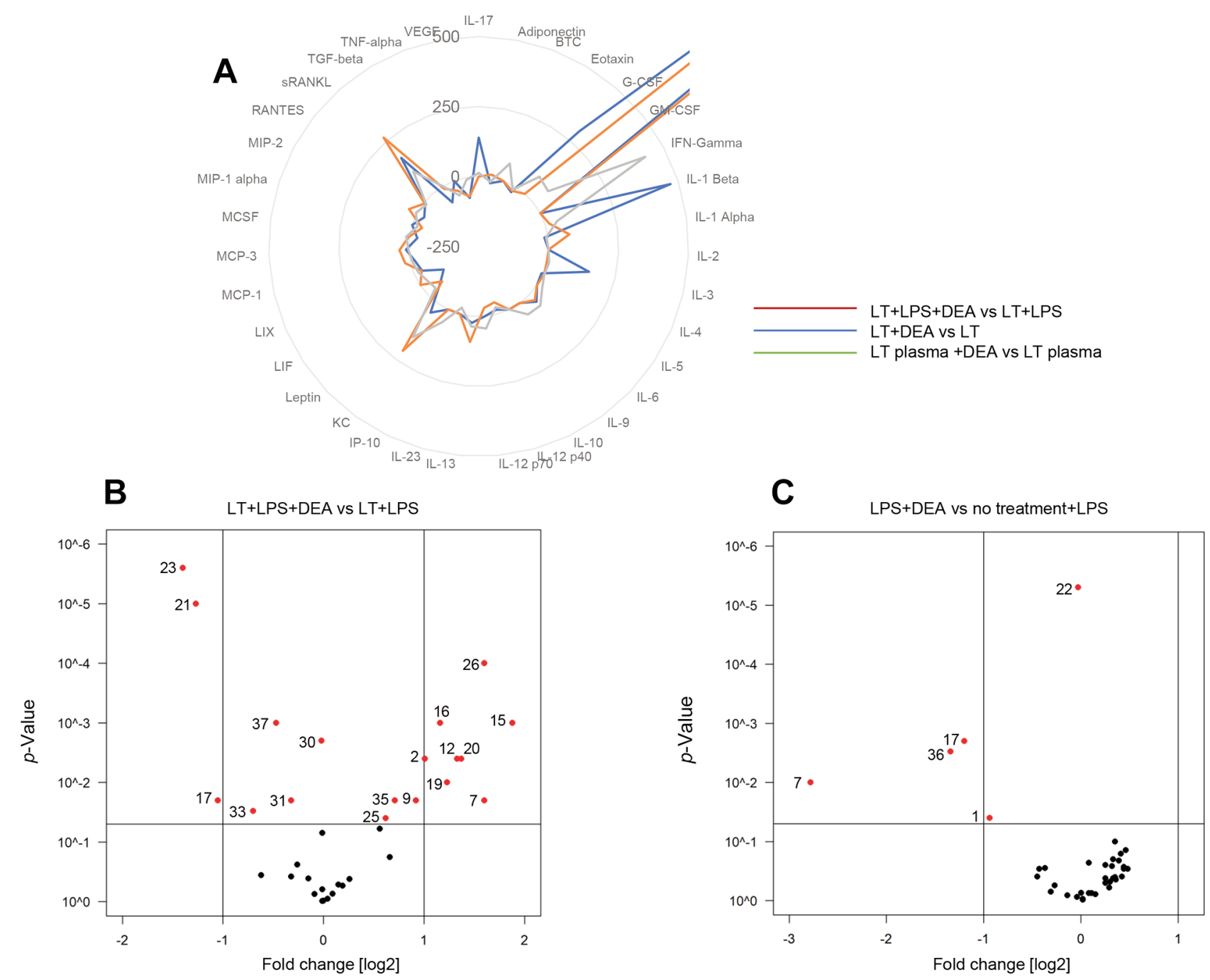

Figure 11. Diethyl azelate interfered with anthrax lethal toxin immunosuppression. A: Mice received lethal toxin (LT) or LT and $0.5 \%$ diethyl azelate (DEA). Plasma and peripheral blood mononuclear cells (PBMCs) were isolated at $24 \mathrm{~h}$ for quantitation of cytokines. Plasma data show the ratios of cytokines in DEA-treated to untreated group (green line). PBMC data show the ratio of DEA-treated to untreated cells with LPS stimulation (red line), or without LPS stimulation (blue line). B: Human PBMCs were incubated $18 \mathrm{~h}$ with LPS, LT and 0.5\% DEA (treated) or LPS and LT (untreated). Cytokine levels were measured in conditioned media. The data is shown as the ratios of cytokines in treated to untreated groups. C: Human PBMCs were incubated $18 \mathrm{~h}$ with LPS and 0.5\% DEA (treated) or LPS alone (untreated). Cytokine levels were measured in conditioned media. The data is shown as the ratios of cytokines in treated to untreated groups. In all cases, cytokines were quantified using multiplexed immunoassays. Data points annotated with numbers for significantly affected cytokines are as follows: 1; adiponectin, 2; BTC, 4; G-CSF, 7; IL-10, 8; IL-12p40, 9; IL-12p70, 12; IL-17A, 14; IL-1beta, 15; IL-2, 16; IL-21, 17; IL23p19, 19; IL-4, 20; IL-5, 21; IL-6, 22; IL-9. 23; IP-10, 25; Leptin, 26; LIF, 30; MCP-3, 31; MIP-lalpha, 33; RANTES, 35; TGF-beta, 36; TNF-alpha, 37; VEGF-A.

number and affinity of receptors on human leukocytes (74). Thus, fluctuations in membrane fluidity may affect structures and functions of integral and membrane-associated proteins.

The effect of DEA on cholera toxin signaling has unexpected and important implications for pain management. A recent study described in detail the biochemical mechanisms by which general anesthetics exert their pharmacological effects (56), whereby inhalational anesthetics disrupt the ordering of lipid rafts and by dint of this disruption induce anesthesia. The best-studied lipid rafts are membrane domains enriched in cholesterol and sphingomyelin (e.g., monosialotetrahexosylganglioside1; GM1) that bind cholera toxin B (CTxB). GM1 lipid rafts contain phospholipase D2 (PLD2). Inhalational anesthetics increase the fluidity of, and thereby disrupt GM1 lipid rafts causing PLD2 to depart the lipid raft and translocate to the proximity of TREK1. Once there, PLD2 hydrolyzes phosphatidylcholine (PC) to produce phosphatidic acid (PA) 
A

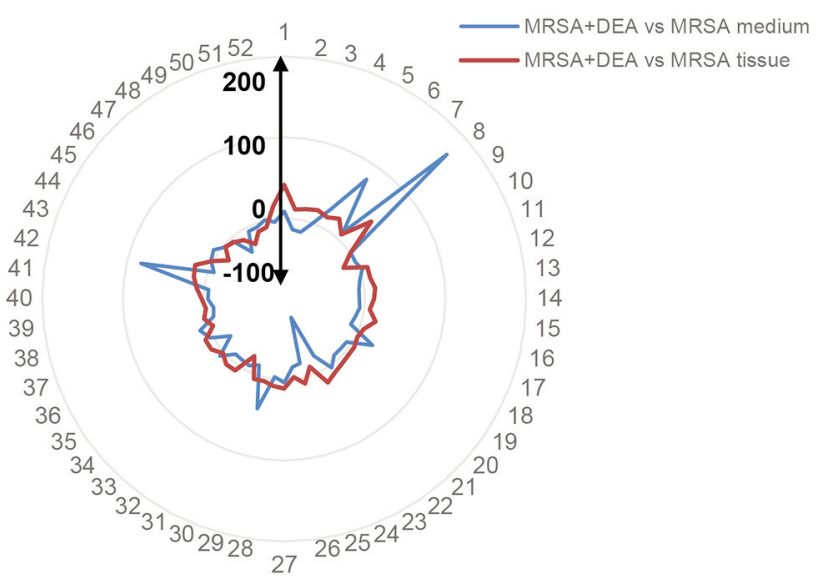

B



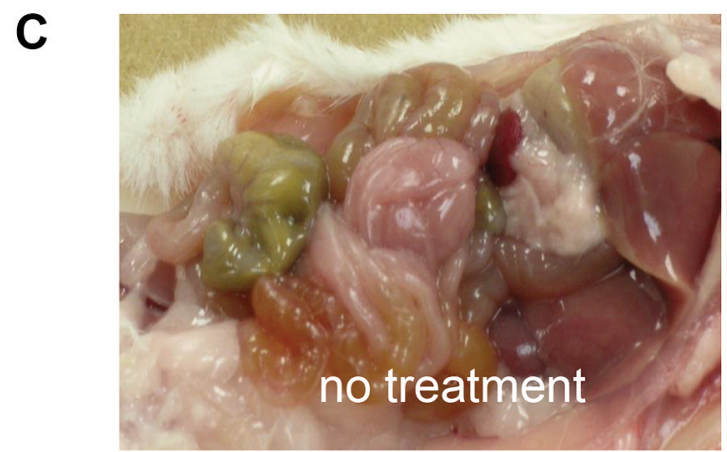

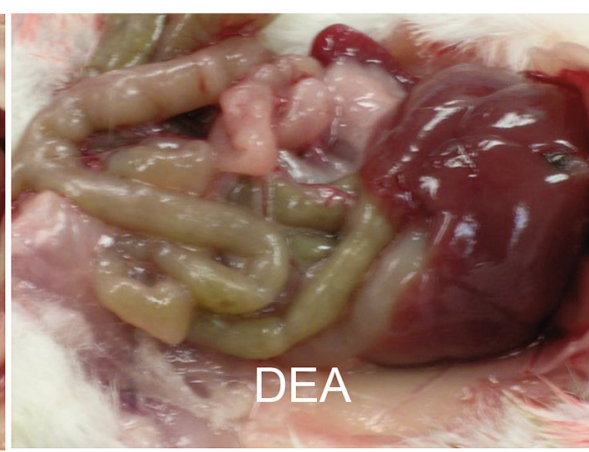

Figure 12. In vitro and in vivo efficacy of diethyl azelate against infections with Panton-Valentine leukocidin-positive methicillin-resistant Staphylococcus aureus [PVL(+) MRSA]. A: EpiDerm tissues were treated with PVL(+) MRSA lysate alone or in the presence of diethyl azelate (DEA). Cytokine levels were measured in conditioned media and tissue lysates using multiplexed immunoassays. The cytokines displayed as numbers on the circumference of the radar plot were: 1 ; IL-Ib, 2; IL-1a, 3; IL-2, 4; IL-4. 5; IL-5. 6; IL-6, 7;IL-7, 8; IL-8. 9; IL-10, I0; IL-12 p40, I1; IL17,12; IFN gamma, 13; GM-CSF. 14; TNF alpha, 15; MPO, 16; sFAS, 17; sFAS ligand, 18; TGF alpha, 19; G-CSF, 20; MIP-1 alpha, 21; MIP-1 beta, 22; eotaxin, 23; VEGF, 24; leptin, 25; IL-10, 26; RANTES, 27; MCP-1, 28; CRP, 29; IL-1 receptor agonist (IL-1 ra), 30; IL-15, 31; adiponectin, 32; resistin, 33; VCAM-1. 34; SAP, 35; PAI-1, 36; fractalkine, 37; ICAM-1, 38; I-TAC, 39; SAA, 40; sE-selectin, 41; HGF, 42; MIF, 43; EGF, 44; sCD40 ligand, 45; MMP-2, 46; MMP-1, 47; MMP-3, 48; MMP-9, 49; MMP-13, 50; MMP-12, 51; MMP-7. 52; MMP-8. The results are shown as percentage differences between the ratios of biomarkers in DEA-treated to untreated media and tissue lysates (vertical arrows inside the radar plot). B: Ten female mice per group were injected intraperitoneally with $10^{6}$ CFU PVL(+) MRSA. DEA (1\%) and erythromycin (ERY) were administered $3 \times$ daily by intraperitoneal injection. The experiment was terminated at $76 \mathrm{~h}$. The results are representative of two independent experiments ( $n=10$ animals per group). C: Preservation of internal organ structure by DEA; representative images from the experiment described under B. No treatment: internal organs such as intestines and liver are largely disintegrated and liquefied.DEA; intestines and liver appear normal.

and choline. The PA then binds to and activates TREK1. When TREK 1 is activated the resultant potassium influx induces unconsciousness and analgesia.

We cannot rule out a possibility that DEA and other azelates may also exert biological effects by binding to their specific receptor(s). This notion is supported by a nonlinear dose-dependent effects of DEA (32) and a rapid onset and reversible activity at low micromolar doses of DEA in mammalian systems (unpublished data). Azelaic acid has a specific olfactory receptor, Olfr544, in mice (81). This receptor is expressed in several non-olfactory murine tissues, is highly abundant in muscle, and its activation by azelaic acid activates mitochondrial biogenesis (82). The human protein analogue is encoded by the OR52K1 gene. Olfactory receptors belong to the $G$ protein-coupled receptors superfamily, the largest class of membrane protein in the human genome with nearly 1000 known members $(83,84)$. Furthermore, the olfactory receptors belong to yet larger family of chemoreceptors, also known as chemosensors. In vertebrates, the chemoreceptors include sensory receptors 


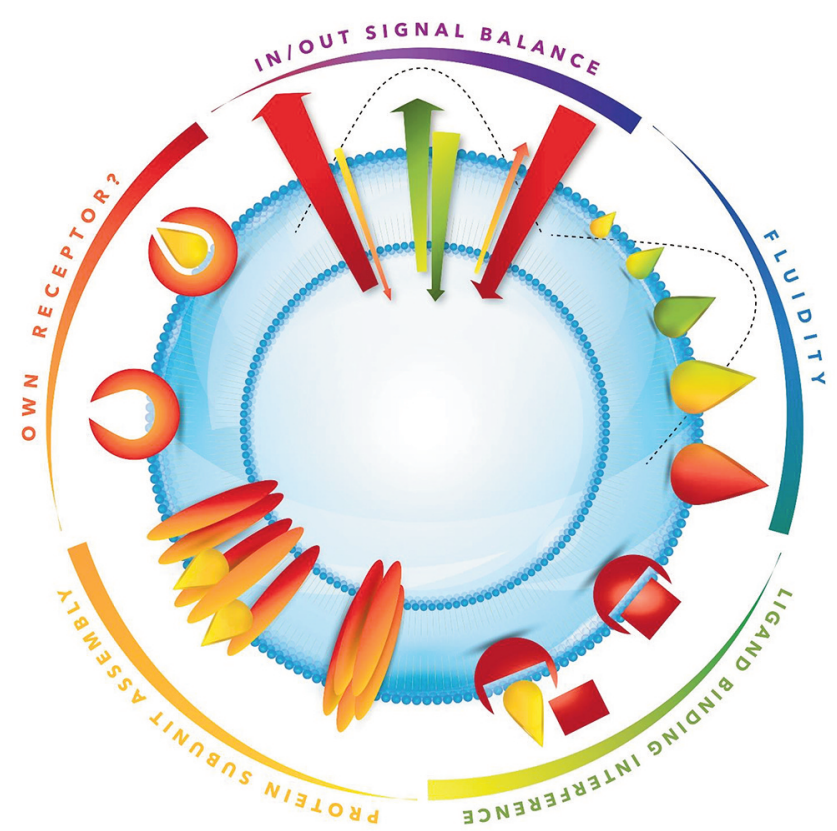

Figure 13. Schematic representation of the mechanism of action of azelates. The plasma membrane bilayer is shown as two concentric blue circles. Clockwise from the top: In/out signal balance; normal homeostatic cellular signaling (green arrows under the peak of the bell curve, comparable arrow sizes indicate balanced signaling) can become imbalanced in disease (red arrows; different sizes indicate imbalanced signaling). Fluidity; increasing doses of an azelate depicted as drops of increasing sizes increases the membrane fluidity with an optimal dose indicated by the peak of the bell curve. Membrane fluidity that is too high or too low is not beneficial. Ligand binding interference; a ligand binding to a receptor can be modulated by an azelate. Protein subunit assembly; multimeric protein assembly can be interfered by an azelate. Own receptor; the existence of a specific azelate receptor has not been identified.

which provide the sensations of smell or taste, and dangersensing PAMP receptors. Plants also have PAMP receptors and induce systemic defense responses when infected by pathogens that result in increased accumulation of azelaic acid (19), (85). Interestingly, the levels of azelaic acid and its esters have been shown to increase upon dioxin intoxication in mice (24). Thus, the immunomodulatory role of azelaic acid and its esters is apparently conserved across kingdoms of living organisms from plants to animals.

Since olfactory receptors interact with multiple ligands with varying affinities related to ligand molecular volumes, and one ligand may bind to different receptors (86), our results on DEA affecting PAMP signaling across many receptor types suggests that azelates indeed have cellular receptors. Direct evidence of $\mathrm{G}$ protein-coupled receptors interaction with the plasma membrane came from a report that described interactions between distinct residues in the $\mathrm{G}$ protein subunits and polar head groups in the phospholipid bilayer (87).
Azelates as potential drugs, membrane active immunomodulators. We have demonstrated clinical activity of DEA on mitigation of insulin resistance in obese individuals (31). Examples of in vivo activity of DEA against PVL(+)MRSA and anthrax toxin suggest that DEA may be useful for the treatment of these diseases. As presented in the current study, the activity of DEA as a pan-PAMP receptor modulator capable of suppressing exuberant cytokine production deserves attention as cytokine storms initiated by bacterial and viral pathogens (88) exact a heavy toll on human life, in particular, the pandemic coronavirus disease COVID-19 cases with severe cytokine storm syndrome and hyperinflammation $(89,90)$.

Targeting cytokine storm with drugs (91) has met many challenges including limitations of targeted therapy against single cytokines. Many of the cytokines down-regulated by DEA treatment taken separately have either been considered or are currently used in targeted therapies $(88,92,93)$. However, to our knowledge, no current drugs can simultaneously affect large numbers of cytokines with minimal side effects the way DEA does.

Given the established role of calcium channels in cytokine trafficking and effects of calcium blockers in modulation of cytokine production $(94,95)$, we propose that DEA may also affect membrane calcium channels with end effects described in this manuscript. Other ion channels and membrane-bound and membrane-associated proteins are also likely to be affected.

Because of their membrane fluidizing activities, DEA and other azelates may also affect the formation of filopodia; cellular "tentacles" that play role in sensing, migration and cell-cell interaction (96), wound closure, and function of neurons, dendritic cells and macrophages (97, 98). Laboratory and clinical data suggest that filopodia have a role in metastasis in cancer (99) and the high infectivity of COVID-19 (100). Interestingly, cancer cells contain elevated levels of cholesterol-containing lipid rafts (101). Since filipodia formation decreases in cells with more fluid plasma membranes (102), possible effects of azelates on filipodia formation may be implicated in the antibacterial/antiviral effects of azelates. Taken together, the azelates have the potential to find application in the treatment of many diseases including autoimmune and cardiovascular diseases, diabetes, cancer, and infectious diseases. DEA may offer a novel approach to treatment of sepsis and bacterial diseases, in general, given the increases in multidrug resistant infections (103) since the development of resistance to DEA is less likely than to standard drugs.

We propose that azelates represent a new class of drugs that modulate cellular communications by the heretofore unappreciated mechanism of action, plasma membrane fluidity modulation. We refer to these molecules as Membrane Active Immunomodulators or MAIMs. We further 
postulate that MAIMs alter plasma membrane fluidity via an innate feedback mechanism, Adaptive Membrane Fluidity Modulation (AMFM), previously unappreciated mechanism by which the plasma membrane fluidity of mammalian cells is actively controlled. This hypothesis is supported by numerous biomedical reports spanning over two centuries.

Our AMFM hypothesis expands and extends the historical concept of homeoviscous adaptation (104). Briefly, the latter is the adaptation of the cell membrane lipid composition to maintain the proper membrane fluidity in bacteria, plants, and animals, especially cold-water fishes and hibernating mammals. The chemical determinant of membrane fluidity is the plasma membrane lipid composition. There is a generally larger proportion of unsaturated fatty acids in the plasma membranes of organisms at lower growth temperatures and a higher proportion of saturated fatty acids at higher temperatures. Although the concept of homeoviscous adaptation has been questioned (105-107), a refreshing look at such adaptation to dietary lipids at the plasma membrane level has been published (108).

In contrast, our AMFM hypothesis proposes a universal mechanism directed to the regulation of biochemical processes driven via the modulation of plasma membrane fluidity that occur under physiological conditions in our bodies in a narrow temperature range of approximately $36.6^{\circ} \mathrm{C}$ (normal body temperature) to $42^{\circ} \mathrm{C}$ (high fever). One manifestation of the importance of the membrane fluidity is that even small departures from the optimal range of body temperatures -either hypothermia or hyperthermia- can rapidly lead to death.

The AMFM hypothesis carries within it important implications for pharmacology. For instance i) diverse types of lipid soluble molecules (MAIMs) affect plasma membrane fluidity, ii) MAIMs interaction with plasma membranes translates to subsequent biological effects, iii) there is a feedback-regulated system that controls plasma membrane fluidity to keep it in the "Goldilocks zone" (named so after a $19^{\text {th }}$ century British fairy tale about a little girl Goldilocks who found "just right" bed to rest in a house of three bears) with an optimal range for individual cells and organisms, and iv) that the process is "druggable", meaning that it can be intentionally modulated and that drugging of this system can induce alterations in circulating and plasma membrane lipid populations.

The AMFM hypothesis does not account for the receptor or molecular target mediated activities of these compounds but it provides insight to the source of those activities that are not accounted for by receptor or specific target effects. Our understanding of the AMFM system opens the door to developing novel treatments for diseases including diabetes, cardiovascular, infectious and autoimmune diseases, stroke, cancer, biodefense indications and many others. AMFM is likely to be a valuable addition and/or complement to the current targeted therapies and receptor-directed model of the mechanisms of action of hormones, drugs and toxins.

\section{Conflicts of Interest}

EI and RTS are the owners and officers of New Frontier Labs, LLC, the sponsor of all studies described in the manuscript.

\section{Authors' Contributions}

EI and RTS conceived the project, performed the studies and wrote the manuscript. CL performed statistical analysis of the results and reviewed the manuscript.

\section{Acknowledgements}

We are indebted to our long-time, now deceased collaborator, Tadeusz Izbicki, M.D Ph.D, for his medical advice, insightful comments, and philosophical discussions that added value to our studies. We are grateful to Richard Luduena Ph.D, for his review of the manuscript and helpful comments.

\section{References}

1 Grecco HE, Schmick M and Bastiaens PI: Signaling from the living plasma membrane. Cell 144(6): 897-909, 2011. PMID: 21414482. DOI: 10.1016/j.cell.2011.01.029

2 Fessler MB and Parks JS: Intracellular lipid flux and membrane microdomains as organizing principles in inflammatory cell signaling. J Immunol 187(4): 1529-1535, 2011. PMID: 21810617. DOI: $10.4049 /$ jimmunol.1100253

3 Schoeniger A, Adolph S, Fuhrmann H and Schumann J: The impact of membrane lipid composition on macrophage activation in the immune defense against Rhodococcus equi and Pseudomonas aeruginosa. Int J Mol Sci 12(11): 7510-7528, 2011. PMID: 22174614. DOI: 10.3390/ijms 12117510

4 Simons K and Toomre D: Lipid rafts and signal transduction. Nat Rev Mol Cell Biol 1(1): 31-39, 2000. PMID: 11413487. DOI: $10.1038 / 35036052$

5 Munro S: Lipid rafts: elusive or illusive? Cell 115(4): 377-388, 2003. PMID: 14622593. DOI: 10.1016/s0092-8674(03)00882-1

6 Komura N, Suzuki KG, Ando H, Konishi M, Koikeda M, Imamura A, Chadda R, Fujiwara TK, Tsuboi H, Sheng R, Cho W, Furukawa K, Furukawa K, Yamauchi Y, Ishida H, Kusumi A and Kiso M: Raft-based interactions of gangliosides with a GPI-anchored receptor. Nat Chem Biol 12(6): 402-410, 2016. PMID: 27043189. DOI: 10.1038/nchembio.2059

7 Kinoshita M, Suzuki KGN, Murata M and Matsumori N: Evidence of lipid rafts based on the partition and dynamic behavior of sphingomyelins. Chem Phys Lipids 215: 84-95, 2018. PMID: 30005889. DOI: 10.1016/j.chemphyslip.2018.07.002

8 Dawaliby R, Trubbia C, Delporte C, Noyon C, Ruysschaert JM, Van Antwerpen P and Govaerts C: Phosphatidylethanolamine is a key regulator of membrane fluidity in eukaryotic cells. J Biol Chem 291(7): 3658-3667, 2016. PMID: 26663081. DOI: 10.1074/jbc.M115.706523

9 Yeagle PL: Cholesterol and the cell membrane. Biochim Biophys Acta 822(3-4): 267-287, 1985. PMID: 3904832. DOI: 10.1016/0304-4157(85)90011-5 
10 Subczynski WK and Wisniewska A: Physical properties of lipid bilayer membranes: relevance to membrane biological functions. Acta Biochim Pol 47(3): 613-625, 2000. PMID: 11310964.

11 Owen DM, Williamson DJ, Magenau A and Gaus K: Subresolution lipid domains exist in the plasma membrane and regulate protein diffusion and distribution. Nat Commun 3: 1256, 2012. PMID: 23212385. DOI: 10.1038/ncomms 2273

12 Owen JS, Bruckdorfer KR, Day RC and McIntyre N: Decreased erythrocyte membrane fluidity and altered lipid composition in human liver disease. J Lipid Res 23(1): 124-132, 1982. PMID: 7057101.

13 Kojima K: Molecular aspects of the plasma membrane in tumor cells. Nagoya J Med Sci 56(1-4): 1-18, 1993. PMID: 7898547.

14 Tokumasu F, Ostera GR, Amaratunga C and Fairhurst RM: Modifications in erythrocyte membrane zeta potential by Plasmodium falciparum infection. Exp Parasitol 131(2): 245-251, 2012. PMID: 22459624. DOI: 10.1016/j.exppara.2012.03.005

15 Kopecka J, Trouillas P, Gašparović AČ, Gazzano E, Assaraf YG and Riganti C: Phospholipids and cholesterol: Inducers of cancer multidrug resistance and therapeutic targets. Drug Resist Updat 49: 100670, 2020. PMID: 31846838. DOI: 10.1016/ j.drup.2019.100670

16 Arispe N and Doh M: Plasma membrane cholesterol controls the cytotoxicity of Alzheimer's disease AbetaP (1-40) and (142) peptides. FASEB J 16(12): 1526-1536, 2002. PMID: 12374775. DOI: 10.1096/fj.02-0829com

17 Goluszko P and Nowicki B: Membrane cholesterol: a crucial molecule affecting interactions of microbial pathogens with mammalian cells. Infect Immun 73(12): 7791-7796, 2005. PMID: 16299268. DOI: 10.1128/IAI.73.12.7791-7796.2005

18 Wang SS, Rymer DL and Good TA: Reduction in cholesterol and sialic acid content protects cells from the toxic effects of beta-amyloid peptides. J Biol Chem 276(45): 42027-42034, 2001. PMID: 11557751. DOI: 10.1074/jbc.M102834200

19 Jung HW, Tschaplinski TJ, Wang L, Glazebrook J and Greenberg JT: Priming in systemic plant immunity. Science 324(5923): 89-91, 2009. PMID: 19342588. DOI: $10.1126 /$ science. 1170025

20 Breathnach AS, Nazzaro-Porro M and Passi S: Azelaic acid. Br J Dermatol 111(1): 115-120, 1984. PMID: 6234914. DOI: 10.1111/j.1365-2133.1984.tb04025.x

21 Schallreuter KU and Wood JW: A possible mechanism of action for azelaic acid in the human epidermis. Arch Dermatol Res 282(3): 168-171, 1990. PMID: 2114832. DOI: 10.1007/BF00372617

22 Fitton A and Goa KL: Azelaic acid. A review of its pharmacological properties and therapeutic efficacy in acne and hyperpigmentary skin disorders. Drugs 41(5): 780-798, 1991. PMID: 1712709. DOI: 10.2165/00003495-199141050-00007

23 Smilowitz JT, O’Sullivan A, Barile D, German JB, Lönnerdal $\mathrm{B}$ and Slupsky CM: The human milk metabolome reveals diverse oligosaccharide profiles. J Nutr 143(11): 1709-1718, 2013. PMID: 24027187. DOI: $10.3945 /$ jn.113.178772

24 Matsubara T, Tanaka N, Krausz KW, Manna SK, Kang DW, Anderson ER, Luecke H, Patterson AD, Shah YM and Gonzalez FJ: Metabolomics identifies an inflammatory cascade involved in dioxin- and diet-induced steatohepatitis. Cell Metab 16(5): 634-644, 2012. PMID: 23140643. DOI: 10.1016/j.cmet. 2012.10.006

25 Fan H, Fan W and Xu Y: Characterization of key odorants in Chinese chixiang aroma-type liquor by gas chromatography- olfactometry, quantitative measurements, aroma recombination, and omission studies. J Agric Food Chem 63(14): 3660-3668, 2015. PMID: 25797496. DOI: 10.1021/jf506238f

26 Saerens SM, Delvaux F, Verstrepen KJ, Van Dijck P, Thevelein JM and Delvaux FR: Parameters affecting ethyl ester production by Saccharomyces cerevisiae during fermentation. Appl Environ Microbiol 74(2): 454-461, 2008. PMID: 17993562. DOI: 10.1128/AEM.01616-07

27 Kostelenos G and Kiritsakis A: Olive tree history and evolution. In: Olives and olive oil as functional foods. Kiritsakis A and Shahidi F (eds.). John Wiley \& Sons Ltd, Oxford, UK, pp. 112, 2017.

28 Rahmani M: Food hazards and quality control in table olive processing with a special reference to functional compounds. In: Olives and olive oil as functional foods. Kiritsakis A and Shahidi F (eds.). John Wiley \& Sons Ltd, Oxford, UK, pp. 347352,2017

29 Hymowitz T: The history of the soybean. In: Soybeans chemistry, production, processing and utilization. AOCS Press pp. 1-31, 2008.

30 Kwon DY, Daily JW 3rd, Kim HJ and Park S: Antidiabetic effects of fermented soybean products on type 2 diabetes. Nutr Res 30(1): 1-13, 2010. PMID: 20116654. DOI: 10.1016/ j.nutres.2009.11.004

31 Streeper RT, Louden C and Izbicka E: Oral azelaic acid ester decreases markers of insulin resistance in overweight human male subjects. In Vivo 34(3): 1173-1186, 2020. PMID: 32354907. DOI: 10.21873/invivo. 11890

32 Streeper RT, Izbicka E, inventors: New Frontier Labs, LLC, assignee. US Patent Azelaic acid esters in the treatment of insulin resistance. USA patent US 10,251,857 B2. 2019.

33 Streeper RT, Izbicka E, inventors: New Frontier Labs LLC, assignee. Azelaic acid esters in the treatment of dyslipidemia and associated conditions. USA patent application 2020.

34 Furniss B, Hannaford A, Smith P and Tatchell A: Vogel's textbook of practical organic chemistry $5^{\text {th }}$ edn. Longman Science \& Technical, London, pp. 695-704, 1996.

35 Streeper R, Diaz A, Campos D, Michalek J, Louden C, Furmaga $\mathrm{W}$ and Izbicka E: Syntra-5 downregulates inflammatory signalling in obese type 2 diabetes murine model in vivo. Curr Top Nutraceutical Res 9: 1-12, 2011.

36 Izbicka E, Streeper RT, Michalek JE, Louden CL, Diaz A 3rd and Campos DR: Plasma biomarkers distinguish non-small cell lung cancer from asthma and differ in men and women. Cancer Genomics Proteomics 9(1): 27-35, 2012. PMID: 22210046.

37 Ridings JE, Barratt MD, Cary R, Earnshaw CG, Eggington CE, Ellis MK, Judson PN, Langowski JJ, Marchant CA, Payne MP, Watson WP and Yih TD: Computer prediction of possible toxic action from chemical structure: an update on the DEREK system. Toxicology 106(1-3): 267-279, 1996. PMID: 8571398. DOI: $10.1016 / 0300-483 \times(95) 03190-q$

38 Hayden P, Bachelor M, Ayehunie S, Letasiova S, Kaluzhny Y, Klausner $\mathrm{M}$ and Kandárová $\mathrm{H}$ : Application of MatTek in vitro reconstructed human skin models for safety, efficacy screening, and basic preclinical research. Appl In Vitro Toxicol 1(3), 2015. DOI: 10.1089/aivt.2015.0012

39 Raffy S and Teissié J: Control of lipid membrane stability by cholesterol content. Biophys J 76(4): 2072-2080, 1999. PMID: 10096902. DOI: 10.1016/S0006-3495(99)77363-7 
40 Galla HJ and Luisetti J: Lateral and transversal diffusion and phase transitions in erythrocyte membranes. An excimer fluorescence study. Biochim Biophys Acta 596(1): 108-117, 1980. PMID: 7353003. DOI: 10.1016/0005-2736(80)90174-1

41 Lingwood D and Simons K: Lipid rafts as a membraneorganizing principle. Science 327(5961): 46-50, 2010. PMID: 20044567. DOI: $10.1126 /$ science. 1174621

42 Male D, Stokes Peebles R, Jr. and Male V: Immunology. Elsevier, 2021.

43 Ballard DH, Cho J and Zhao H: Comparisons of multi-marker association methods to detect association between a candidate region and disease. Genet Epidemiol 34(3): 201-212, 2010. PMID: 19810024. DOI: 10.1002/gepi.20448

44 Takeda K and Akira S: Toll-like receptors in innate immunity. Int Immunol 17(1): 1-14, 2005. PMID: 15585605. DOI: 10.1093/intimm/dxh186

45 Akira S, Takeda $\mathrm{K}$ and Kaisho T: Toll-like receptors: critical proteins linking innate and acquired immunity. Nat Immunol 2(8): 675-680, 2001. PMID: 11477402. DOI: 10.1038/90609

46 Aderem A and Ulevitch RJ: Toll-like receptors in the induction of the innate immune response. Nature 406(6797): 782-787, 2000. PMID: 10963608. DOI: $10.1038 / 35021228$

47 Burgueño JF and Abreu MT: Epithelial Toll-like receptors and their role in gut homeostasis and disease. Nat Rev Gastroenterol Hepatol 17(5): 263-278, 2020. PMID: 32103203. DOI: 10.1038/s41575-019-0261-4

48 Kufer TA, Banks DJ and Philpott DJ: Innate immune sensing of microbes by Nod proteins. Ann N Y Acad Sci 1072: 19-27, 2006. PMID: 17057187. DOI: 10.1196/annals.1326.020

49 Drummond RA and Brown GD: The role of Dectin-1 in the host defence against fungal infections. Curr Opin Microbiol 14(4): 392-399, 2011. PMID: 21803640. DOI: 10.1016/j.mib. 2011.07.001

50 Matzinger P: The danger model: a renewed sense of self. Science 296(5566): 301-305, 2002. PMID: 11951032. DOI: $10.1126 /$ science. 1071059

51 Kaufmann A, Musset B, Limberg SH, Renigunta V, Sus R, Dalpke AH, Heeg KM, Robaye B and Hanley PJ: "Host tissue damage" signal ATP promotes non-directional migration and negatively regulates toll-like receptor signaling in human monocytes. J Biol Chem 280(37): 32459-32467, 2005. PMID: 16030017. DOI: 10.1074/jbc.M505301200

52 Vaure C and Liu Y: A comparative review of toll-like receptor 4 expression and functionality in different animal species. Front Immunol 5: 316, 2014. PMID: 25071777. DOI: 10.3389/fimmu. 2014.00316

53 Woolhouse MEJ and Brierley L: Epidemiological characteristics of human-infective RNA viruses. Sci Data 5: 180017, 2018. PMID: 29461515. DOI: 10.1038/sdata.2018.17

54 Liu Y, Liao W, Wan L, Xiang T and Zhang W: Correlation between relative nasopharyngeal virus RNA load and lymphocyte count disease severity in patients with COVID-19. Viral Immunol 34(5): 330-335, 2021. PMID: 32297828. DOI: $10.1089 /$ vim.2020.0062

55 Roach JC, Glusman G, Rowen L, Kaur A, Purcell MK, Smith KD, Hood LE and Aderem A: The evolution of vertebrate Tolllike receptors. Proc Natl Acad Sci U.S.A. 102(27): 9577-9582, 2005. PMID: 15976025. DOI: 10.1073/pnas.0502272102

56 Pavel MA, Petersen EN, Wang H, Lerner RA and Hansen SB: Studies on the mechanism of general anesthesia. Proc Natl
Acad Sci U.S.A. 117(24): 13757-13766, 2020. PMID: 32467161. DOI: 10.1073/pnas.2004259117

57 Sánchez J and Holmgren J: Cholera toxin structure, gene regulation and pathophysiological and immunological aspects. Cell Mol Life Sci 65(9): 1347-1360, 2008. PMID: 18278577. DOI: $10.1007 / \mathrm{s} 00018-008-7496-5$

58 Ray S, Taylor M, Banerjee T, Tatulian SA and Teter K: Lipid rafts alter the stability and activity of the cholera toxin A1 subunit. J Biol Chem 287(36): 30395-30405, 2012. PMID: 22787142. DOI: $10.1074 /$ jbc.M112.385575

59 Blank N, Schiller M, Krienke S, Wabnitz G, Ho AD and Lorenz HM: Cholera toxin binds to lipid rafts but has a limited specificity for ganglioside GM1. Immunol Cell Biol 85(5): 378382, 2007. PMID: 17325693. DOI: 10.1038/sj.icb.7100045

60 Baldari CT, Tonello F, Paccani SR and Montecucco C: Anthrax toxins: A paradigm of bacterial immune suppression. Trends Immunol 27(9): 434-440, 2006. PMID: 16861036. DOI: 10.1016/j.it.2006.07.002

61 Leppla SH: Anthrax toxin. In: Handbook of experimental pharmacology. Aktories K and Just I (eds.). Springer-Verlag, 2000.

62 Moayeri M and Leppla SH: Cellular and systemic effects of anthrax lethal toxin and edema toxin. Mol Aspects Med 30(6): 439-455, 2009. PMID: 19638283. DOI: 10.1016/j.mam. 2009.07.003

63 Abramova F, Grinberg L, Yampolskaya $\mathrm{O}$ and Walker D: Pathology of inhalational anthrax in 42 cases from the Sverdlovsk outbreak of 1979. Proceedings of the National Academy of Sciences 90(6): 2291-2294, 2016. DOI: 10.1073/ pnas.90.6.2291

64 Meselson M, Guillemin J, Hugh-Jones M, Langmuir A, Popova I, Shelokov A and Yampolskaya O: The Sverdlovsk anthrax outbreak of 1979. Science 266(5188): 1202-1208, 1994. PMID: 7973702. DOI: 10.1126/science. 7973702

65 Hanna P: Lethal toxin actions and their consequences. J Appl Microbiol 87(2): 285-287, 1999. PMID: 10475969. DOI: 10.1046/j.1365-2672.1999.00891.x

66 Robson WP and Daniel R: The Sepsis Six: helping patients to survive sepsis. Br J Nurs 17(1): 16-21, 2008. PMID: 18399392. DOI: 10.12968/bjon.2008.17.Sup1.28145

67 Irazoqui JE, Troemel ER, Feinbaum RL, Luhachack LG, Cezairliyan BO and Ausubel FM: Distinct pathogenesis and host responses during infection of $\mathrm{C}$. elegans by $\mathrm{P}$. aeruginosa and S. aureus. PLoS Pathog 6: e1000982, 2010. PMID: 20617181. DOI: 10.1371/journal.ppat.1000982

68 Kellum JA, Kong L, Fink MP, Weissfeld LA, Yealy DM, Pinsky MR, Fine J, Krichevsky A, Delude RL, Angus DC and GenIMS Investigators: Understanding the inflammatory cytokine response in pneumonia and sepsis: results of the Genetic and Inflammatory Markers of Sepsis (GenIMS) Study. Arch Intern Med 167(15): 1655-1663, 2007. PMID: 17698689. DOI: $10.1001 /$ archinte.167.15.1655

69 Wang L, Zhao H and Wang D: Inflammatory cytokine expression in patients with sepsis at an intensive care unit. Exp Ther Med 16(3): 2126-2131, 2018. PMID: 30186449. DOI: 10.3892/etm.2018.6376

$70 \mathrm{Yu}$ WK, Li WQ, Li N and Li JS: Influence of acute hyperglycemia in human sepsis on inflammatory cytokine and counterregulatory hormone concentrations. World J Gastroenterol 9(8): 1824-1827, 2003. PMID: 12918129. DOI: 10.3748/wjg.v9.i8.1824 
71 Shapiro NI, Khankin EV, Van Meurs M, Shih SC, Lu S, Yano M, Castro PR, Maratos-Flier E, Parikh SM, Karumanchi SA and Yano K: Leptin exacerbates sepsis-mediated morbidity and mortality. J Immunol 185(1): 517-524, 2010. PMID: 20519646. DOI: 10.4049 jimmunol.0903975

72 Charnock C, Brudeli B and Klaveness J: Evaluation of the antibacterial efficacy of diesters of azelaic acid. Eur J Pharm Sci 21(5): 589-596, 2004. PMID: 15066659. DOI: 10.1016/ j.ejps.2003.12.006

73 Heron DS, Shinitzky M, Hershkowitz M and Samuel D: Lipid fluidity markedly modulates the binding of serotonin to mouse brain membranes. Proc Natl Acad Sci U.S.A. 77(12): 7463-7467, 1980. PMID: 6938985. DOI: 10.1073/pnas. 77.12 .7463

74 Tomonaga A, Hirota M and Snyderman R: Effect of membrane fluidizers on the number and affinity of chemotactic factor receptors on human polymorphonuclear leukocytes. Microbiol Immunol 27(11): 961-972, 1983. PMID: 6321913. DOI: 10.1111/j.1348-0421.1983.tb00662.x

75 Gupta MN: Enzyme function in organic solvents. Eur J Biochem 203(1-2): 25-32, 1992. PMID: 1730231. DOI: 10.1111/j.1432-1033.1992.tb19823.x

76 Cui D, Zhang BW, Matubayasi N and Levy RM: The role of interfacial water in protein-ligand binding: insights from the indirect solvent mediated potential of mean force. J Chem Theory Comput 14(2): 512-526, 2018. PMID: 29262255. DOI: 10.1021/acs.jctc.7b01076

77 Ma Y, Poole K, Goyette J and Gaus K: Introducing membrane charge and membrane potential to $\mathrm{T}$ cell signaling. Front Immunol 8: 1513, 2017. PMID: 29170669. DOI: 10.3389/ fimmu.2017.01513

78 Jaqaman $\mathrm{K}$ and Grinstein S: Regulation from within: the cytoskeleton in transmembrane signaling. Trends Cell Biol 22(10): 515-526, 2012. PMID: 22917551. DOI: 10.1016/j.tcb. 2012.07.006

79 Haines T: Do sterols reduce proton and sodium leaks through lipid bilayers? Progress in Lipid Research 40(4): 299-324, 2021. DOI: 10.1016/S0163-7827(01)00009-1

80 de Pablo MA and Alvarez de Cienfuegos G: Modulatory effects of dietary lipids on immune system functions. Immunol Cell Biol 78(1): 31-39, 2000. PMID: 10651927. DOI: 10.1046/ j.1440-1711.2000.00875.x

81 Thach TT, Hong YJ, Lee S and Lee SJ: Molecular determinants of the olfactory receptor Olfr544 activation by azelaic acid. Biochem Biophys Res Commun 485(2): 241-248, 2017. PMID: 28235481. DOI: $10.1016 /$ j.bbrc.2017.02.104

82 Thach TT, Wu C, Hwang KY and Lee SJ: Azelaic acid induces mitochondrial biogenesis in skeletal muscle by activation of olfactory receptor 544. Front Physiol 11: 329, 2020. PMID: 32411005. DOI: 10.3389/fphys.2020.00329

83 Antunes G and Simoes de Souza FM: Olfactory receptor signaling. Methods Cell Biol 132: 127-145, 2016. PMID: 26928542. DOI: 10.1016/bs.mcb.2015.11.003

84 Glezer I and Malnic B: Olfactory receptor function. Handb Clin Neurol 164: 67-78, 2019. PMID: 31604564. DOI: 10.1016/ B978-0-444-63855-7.00005-8

85 Ádám AL, Nagy ZÁ, Kátay G, Mergenthaler E and Viczián O: Signals of systemic immunity in plants: progress and open questions. Int J Mol Sci 19(4): 1146, 2018. PMID: 29642641. DOI: $10.3390 /$ ijms 19041146
86 Saberi M and Seyed-Allaei H: Odorant receptors of Drosophila are sensitive to the molecular volume of odorants. Sci Rep 6: 25103, 2016. PMID: 27112241. DOI: 10.1038/srep25103

87 Yin J, Chen KM, Clark MJ, Hijazi M, Kumari P, Bai XC, Sunahara RK, Barth P and Rosenbaum DM: Structure of a D2 dopamine receptor-G-protein complex in a lipid membrane. Nature 584(7819): 125-129, 2020. PMID: 32528175. DOI: 10.1038/s41586-020-2379-5

88 Tisoncik JR, Korth MJ, Simmons CP, Farrar J, Martin TR and Katze MG: Into the eye of the cytokine storm. Microbiol Mol Biol Rev 76(1): 16-32, 2012. PMID: 22390970. DOI: 10.1128/ MMBR.05015-11

89 Mehta P, McAuley DF, Brown M, Sanchez E, Tattersall RS, Manson JJ and HLH Across Speciality Collaboration, UK: COVID-19: consider cytokine storm syndromes and immunosuppression. Lancet 395(10229): 1033-1034, 2020. PMID: 32192578. DOI: 10.1016/S0140-6736(20)30628-0

90 Henderson LA, Canna SW, Schulert GS, Volpi S, Lee PY, Kernan KF, Caricchio R, Mahmud S, Hazen MM, Halyabar O, Hoyt KJ, Han J, Grom AA, Gattorno M, Ravelli A, De Benedetti F, Behrens EM, Cron RQ and Nigrovic PA: On the alert for cytokine storm: Immunopathology in COVID-19. Arthritis Rheumatol 72(7): 1059-1063, 2020. PMID: 32293098. DOI: $10.1002 /$ art.41285

91 D’Elia RV, Harrison K, Oyston PC, Lukaszewski RA and Clark GC: Targeting the "cytokine storm" for therapeutic benefit. Clin Vaccine Immunol 20(3): 319-327, 2013. PMID: 23283640. DOI: $10.1128 / C V I .00636-12$

92 Weaver LK and Behrens EM: Weathering the storm: Improving therapeutic interventions for cytokine storm syndromes by targeting disease pathogenesis. Curr Treatm Opt Rheumatol 3(1): 33-48, 2017. PMID: 28944163. DOI: 10.1007/s40674-017-0059-x

93 Wang $\mathrm{H}$ and $\mathrm{Ma} \mathrm{S}$ : The cytokine storm and factors determining the sequence and severity of organ dysfunction in multiple organ dysfunction syndrome. Am J Emerg Med 26(6): 711-715, 2008. PMID: 18606328. DOI: 10.1016/j.ajem 2007.10 .031

94 Liu W and Matsumori A: Calcium channel blockers and modulation of innate immunity. Curr Opin Infect Dis 24(3): 254-258, 2011. PMID: 21467929. DOI: 10.1097/QCO 0b013e3283463e 5b

95 Matsumori A, Nishio R and Nose Y: Calcium channel blockers differentially modulate cytokine production by peripheral blood mononuclear cells. Circ J 74(3): 567-571, 2010. PMID: 20118567. DOI: 10.1253/circj.cj-09-0467

96 Mattila PK and Lappalainen P: Filopodia: molecular architecture and cellular functions. Nat Rev Mol Cell Biol 9(6): 446-454, 2008. PMID: 18464790. DOI: $10.1038 / \mathrm{nrm} 2406$

97 Bentley D and Toroian-Raymond A: Disoriented pathfinding by pioneer neurone growth cones deprived of filopodia by cytochalasin treatment. Nature 323(6090): 712-715, 1986. PMID: 3773996. DOI: 10.1038/323712a0

98 Kress H, Stelzer EH, Holzer D, Buss F, Griffiths G and Rohrbach A: Filopodia act as phagocytic tentacles and pull with discrete steps and a load-dependent velocity. Proc Natl Acad Sci U.S.A. 104(28): 11633-11638, 2007. PMID: 17620618. DOI: $10.1073 /$ pnas.0702449104

99 Jacquemet G, Baghirov H, Georgiadou M, Sihto H, Peuhu E, Cettour-Janet P, He T, Perälä M, Kronqvist P, Joensuu H and 
Ivaska J: L-type calcium channels regulate filopodia stability and cancer cell invasion downstream of integrin signalling. Nat Commun 7: 13297, 2016. PMID: 27910855. DOI: 10.1038/ ncomms 13297

100 Bouhaddou M, Memon D, Meyer B, White KM, Rezelj VV, Correa Marrero M, Polacco BJ, Melnyk JE, Ulferts S, Kaake RM, Batra J, Richards AL, Stevenson E, Gordon DE, Rojc A, Obernier K, Fabius JM, Soucheray M, Miorin L, Moreno E, Koh C, Tran QD, Hardy A, Robinot R, Vallet T, Nilsson-Payant BE, Hernandez-Armenta C, Dunham A, Weigang S, Knerr J, Modak M, Quintero D, Zhou Y, Dugourd A, Valdeolivas A, Patil T, Li Q, Hüttenhain R, Cakir M, Muralidharan M, Kim M, Jang G, Tutuncuoglu B, Hiatt J, Guo JZ, Xu J, Bouhaddou S, Mathy CJP, Gaulton A, Manners EJ, Félix E, Shi Y, Goff M, Lim JK, McBride T, O’Neal MC, Cai Y, Chang JCJ, Broadhurst DJ, Klippsten S, De Wit E, Leach AR, Kortemme T, Shoichet B, Ott M, Saez-Rodriguez J, tenOever BR, Mullins RD, Fischer ER, Kochs G, Grosse R, García-Sastre A, Vignuzzi M, Johnson JR, Shokat KM, Swaney DL, Beltrao P and Krogan NJ: The global phosphorylation landscape of SARS-CoV-2 infection. Cell 182(3): 685-712.e19, 2020. PMID: 32645325. DOI: 10.1016/j.cell.2020.06.034

101 Li YC, Park MJ, Ye SK, Kim CW and Kim YN: Elevated levels of cholesterol-rich lipid rafts in cancer cells are correlated with apoptosis sensitivity induced by cholesterol-depleting agents. Am J Pathol 168(4): 1107-18; quiz 1404-5, 2006. PMID: 16565487. DOI: 10.2353/ajpath.2006.050959

102 Khatibzadeh N, Spector AA, Brownell WE and Anvari B: Effects of plasma membrane cholesterol level and cytoskeleton F-actin on cell protrusion mechanics. PLoS One 8(2): e57147, 2013. PMID: 23451167. DOI: 10.1371/journal.pone.0057147

103 Nikaido H: Multidrug resistance in bacteria. Annu Rev Biochem 78: 119-146, 2009. PMID: 19231985. DOI: 10.1146/ annurev.biochem.78.082907.145923
104 Sinensky M: Homeoviscous adaptation - a homeostatic process that regulates the viscosity of membrane lipids in Escherichia coli. Proc Natl Acad Sci USA 71(2): 522-525, 1974. PMID: 4360948. DOI: $10.1073 /$ pnas.71.2.522

105 Cossins AR, Christiansen J and Prosser CL: Adaptation of biological membranes to temperature. The lack of homeoviscous adaptation in the sarcoplasmic reticulum. Biochim Biophys Acta 511(3): 442-452, 1978. PMID: 687623. DOI: $10.1016 / 0005-2736(78) 90280-8$

106 Hazel JR: Thermal adaptation in biological membranes: is homeoviscous adaptation the explanation? Annu Rev Physiol 57: 19-42, 1995. PMID: 7778864. DOI: 10.1146/annurev. ph.57.030195.000315

107 Ballweg S, Sezgin E, Doktorova M, Covino R, Reinhard J, Wunnicke D, Hänelt I, Levental I, Hummer G and Ernst R: Regulation of lipid saturation without sensing membrane fluidity. Nat Commun 11(1): 756, 2020. PMID: 32029718. DOI: $10.1038 / \mathrm{s} 41467-020-14528-1$

108 Zinöcker MK, Svendsen K and Dankel SN: The homeoviscous adaptation to dietary lipids (HADL) model explains controversies over saturated fat, cholesterol, and cardiovascular disease risk. Am J Clin Nutr 113(2): 277-289, 2021. PMID: 33471045. DOI: 10.1093/ajen/nqaa322
Received April 17, 2021

Revised July 21, 2021

Accepted September 1, 2021 